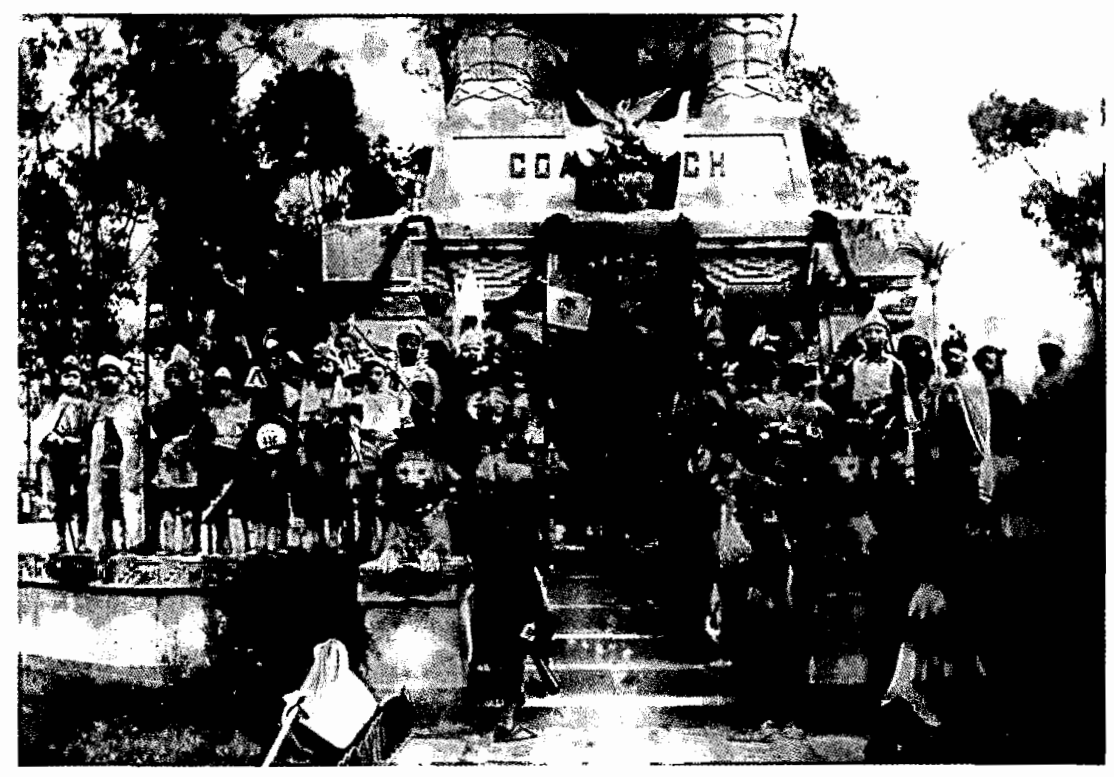




\section{David Mayers}

Doctor por la University of Chicago (1979). Actualmente es profesor del Departamento de Historia del Departamento de Ciencias Políticas de la Boston University. Sus temas de interés son: historia de la política exterior de Estados Unidos, las relaciones internacionales de Europa desde 1789, la biografía política, la historia diplomática de la uRss (Rusia) y China, así como la teoría clásica de las relaciones internacionales. Entre sus publicaciones destacan: Wars and Peace: The Future Americans Envisioned, 1861-1991, St. Martin's Press, Nueva York, 1998 (libro de bolsillo, 1999); The Ambassadors and America's Soviet Policy, Oxford University Press, Nueva York, 1995, ganador del premio de la American Academy of Diplomacy, 1995 (libro de bolsillo, 1997); George Kennan and the Dilemmas of US Foreign Policy, Oxford University Press, Nueva York, 1988 (libro de bolsillo 1990). Editor de Reevaluating Eisenhower: American Foreign Policy in the 1950s, University of Illinois Press, Urbana, 1987. Ha colaborado con capítulos de libros y artículos en revistas especializadas en diplomacia internacional.

\section{Resumen}

Este artículo examina las ideas y la influencia de ciudadanos prominentes de Estados Unidos que objetaron la guerra del presidente James Polk en contra de México, 1846-1848. Las razones para la objeción variaban. Algunos de los disidentes creían que la guerra constituía una agresión injusta. A otros les preocupaba sobre todo la adquisición de tierras nuevas que agravaría la lid en curso entre el Sur plantacionista y el Norte antiesclavista. Otros más no quetían la guerra porque transformaba a Estados Unidos de una república a un rapaz imperio militarista. Los disidentes no se impusieron, pero se expresaron en un tono exaltado y constituyeron un precedente importante para los movimientos antibélicos en la historia de Estados Unidos.

Palabras clave:

Joshua Giddings, Nicholas Philip Trist, John Calhoun, Henry David Thoreau, James Polk.

\section{Abstract}

This article examines the ideas and influence of prominent U.S. citizens who objected to President James Polk's war against Mexico, 18461848. Reasons for objection varied among the dissenters. Some believed the war constituted an unjust aggression. Others were primarily concerned about the acquisition of new lands that would aggravate the ongoing feud berween the plantation South and antislavery North. Still, other dissenters disliked the war for transforming the United States from a republic to a grasping militaristic empire. The dissenters did not prevail. But they did establish a high tone and important precedent for subsequent antiwar movements in U.S. history.

Key words:

Joshua Giddings, Nicholas Philip Trist, John Calhoun, Henry David Thoreau, James Polk.

Fecha de recepción: agosto de 2002

Fecha de aceptación: marzo de 2003 


\title{
La guerra con México y los disidentes estadunidenses, 1846-1848*
}

\author{
David Mayers
}

$\mathbf{E}$ stados Unidos consiguió su más grande extensión territorial durante la presidencia de James Polk (1845-1849). Polk, un expansionista desenfadado, añadió 1200000 millas cuadradas al territorio estadunidense, una hazaña notable que realizó en tres fases.

Primero, la república de Texas, independiente de México desde 1836, se convirtió en el $28^{\circ}$ estado en 1845 . Este suceso, sustancialmente impulsado por el predecesor de Polk, el presidente John Tyler, provocó que el gobierno de la ciudad de México rompiera relaciones con Washington. Texas, en la mentalidad de los círculos oficiales mexicanos, era una provincia en rebeldía -que pertenecía al estado de Coahuila- y era inasequible para ser ocupada por cualquier gobierno extranjero. Sin embargo, Juan N. Almonte, ministro en Washington, sólo pudo protestar por la anexión estadunidense de Texas. La fragilidad política de México impedía cualquier otra acción. ${ }^{1}$

En segundo lugar, la agitada disputa entre Londres y Washington sobre el territorio de Oregón, que provocaba en Polk bravatas y amenazas de un enfrentamiento entre Gran Bretaña, Estados Unidos y Canadá, se resolvió pacíficamente

* Traducción de Sergio A. Fernández Bravo.

${ }^{1}$ Pletcher, Diplomacy, 1973, p. 185. en junio de 1846. El acuerdo por medio del tratado Buchanan-Parkenham ahorró a Estados Unidos una lucha en el noroeste mientras preparaba operaciones en contra de México. Se evitó la guerra en dos zonas. El acuerdo con Gran Bretaña también le dio a Estados Unidos una fachada en el Pacífico, y aseguró tierras que más tarde produjeron tres estados: Oregón, Washington y Idaho (además de partes de Montana).

De manera más dramática, por derecho de conquista, de 1846 a 1848, Polk presidió la anexión a Estados Unidos de vastas posesiones mexicanas. Esta cesión abarcaba más de $40 \%$ del territorio de la república mexicana. De entre las ruinas, dignificadas por el Tratado de Guadalupe-Hidalgo y un precio de compra de 15000000 de pesos, surgieron varios estados: California (con el descubrimiento de oro en 1848), Nevada, Utah, Arizona y Nuevo México (aumentados por el acuerdo Gadsden de 1853); partes de Wyoming, Colorado, Oklahoma, Kansas y Texas. ${ }^{2}$ Aproximadamente 100000 mexicanos también quedaron bajo la autoridad estadunidense.

Subyugado por visiones de un arrollador fundamentalismo democrático, el

\footnotetext{
${ }^{2}$ Weber, Mexican, 1982, p. Xv.
} 
joven Walt Whitman escribió antes del éxito final del ejército de Estados Unidos:

Nos encanta entregarnos a pensamientos sobre la futura extensión y el poderío de esta república -porque su aumento es el aumento de la felicidad y las humanas [...] ¿Qué tiene que hacer el miserable e ineficiente México [...] en la gran misión del poblamiento del nuevo mundo con una raza noble?

Añadía que la aletargada nación latina se beneficiaría con las aplicaciones del tónico estadunidense: gobierno recto, comercio vigoroso y educación liberal. James Fenimore Cooper percibía similares imposiciones contra México al confirmar el impacto regenerativo del poderío de Estados Unidos en el hemisferio occidental. En lo que respecta a Polk, no sólo felicitó a los legisladores en su último mensaje al Congreso (diciembre de 1848) por apoyar los esfuerzos militares de la administración y por aprobar el tratado de paz que produjo nuevas posesiones. También afirmó que la abundancia y la felicidad reinaban en la Tierra. Halagó la vanidad colectiva: "Nuestro amado país presenta un sublime espectáculo moral al mundo." 3

El creciente poderío celebrado por Polk y otros entusiastas del Destino Manifiesto no fue aplaudido en México. El recuerdo de la invasión estadunidense se ulceraba como herida en la generación de la guerra y en sus sucesores. El resenti-

${ }^{3}$ Walt Whitman citado en Ruiz, Mexican, 1963 , p. 8; McDougall, Promised, 1997, p. 93; Bauer, Mexican, 1974, p. Xvir; Polk's Fourth Annual Message, 5 de diciembre de 1848 en Richardson, Messages, 1897, vol. v, p. 2479. miento fusionaba republicanos anticlericales con sus antagonistas - con conservadores militares y los tradicionalistas eclesiales- en solidaridad con el país desposeído. Antonio López de Santa Anna, el antiguo líder de México, condenaba en sus memorias a Estados Unidos por iniciar la guerra y luego imponer una paz extrema. El premio Nobel Octavio Paz afirmó, más de un siglo después del conflicto, que Estados Unidos había dirigido "una de las guerras más injustas en la historia de la expansión imperialista". La erudición mexicana subsiguiente ha argumentado que el cercenamiento de territorios valiosos obstruyó la modernización nacional durante décadas. El dolor de la derrota fue aliviado en la mente popular sólo por la leyenda de los valientes niños héroes que se opusieron a los "vándalos" estadunidenses en la batalla culminante de Chapultepec, en septiembre de 1847.4

Aunque satisfecho por el dominio del ejército en esas batallas, el público estadunidense se dividió sobre la conveniencia de pelear con México. No hubo nada parecido a un consenso que apoyara la guerra de Polk. Al prolongarse mucho, en 1847, sin posibilidades de conclusión a la vista, los partidarios de todo tipo refunfuñaban por los cada vez mayores costos y las implicaciones morales y políticas. ${ }^{5}$ Ninguna guerra extranjera irritaría en forma semejante al Congreso y al público hasta Vietnam, en los años 1960.

Hablando a grandes rasgos, la guerra contra México gozó de mayor apoyo en

${ }^{4}$ Crawford, Eagle, 1967, pp. 88, 115; Paz, Labyrinth, 1961, p. 124; Castillo, Treaty, 1990, p. XI; Robinson, View, 1989, p. IX.

${ }^{5}$ Haynes, James, 1997, p. 168. 
el Oeste y el nuevo Sur (Texas y los estados unidos por el río Mississippi). Esta región proporcionó el grueso de militares y voluntarios. El primer lote de 50000 hombres reforzó crucialmente al ejército regular, de apenas 7500 soldados en 1846. El Noreste y el antiguo Sur, en contraste, no estaban entusiasmados con la campaña mexicana. La nómina de los trece estados originales llegaba a escasos 13000 hombres. Nueva Inglaterra disintió por completo. La legislatura de Massachusetts denunció el combate como anticonstitucional. ${ }^{6}$

Henri David Thoreau justificó, en su cabaña de Walden, la desobediencia civil en su defensa por no pagar el impuesto del voto. En consecuencia pasó una noche en la cárcel de Concord. Calificó la guerra como una agresión flagrante, apoyada en el interés de los dueños de esclavos deseosos de ampliar la extensión de sus plantaciones. La situación requería de alguien consciente para resistir negando el apoyo a la autoridad establecida. Todavía mejor, alguien que pudiera subvertirla:

Cuando una sexta parte de la población de una nación que ha determinado ser el refugio de la libertad es esclava, y todo un país es injustamente invadido y conquistado por un ejército extranjero, y sometido a un gobierno militar, creo que no es demasiado pronto para que los hombres honestos se rebelen y se hagan revolucionarios. Lo que hace su deber más urgente es el hecho de que ese país así invadido no es el nuestro, sino nuestro es el ejército invasor. ${ }^{7}$

\footnotetext{
${ }^{6}$ Morison, Oxford, 1965, pp. 561-562; Bauer, Mexican, 1974, p. 364.

${ }^{7}$ Rossi, Henry, 1992, p. 229.
}

En el cercano Boston, William Lloyd Garrison se opuso también a la guerra. Pensó que Massachusetts sería mejor servida abandonando la injusta Unión, lo cual solicitó de la legislatura estatal. Presentó 2800 firmas de apoyo. También se declaró a favor de la victoria de México. $\mathrm{El}$ inconmovible abolicionista Theodor Parker condenó la guerra desde su púlpito (en la $28^{a}$ Iglesia Congregacional de Boston). Suavizó sus apreciaciones sólo al admitir que la civilización anglosajona era superior a la del decadente México. La guerra, en general, predicaba, violaba preceptos cristianos de misericordia y hermandad. La guerra también ponía en peligro los hábitos democráticos de la mente, glorificaba a hombres vulgares y despilfarraba la salud pública. La guerra mexicana era especialmente inicua, ya que su objetivo era extender la zona de esclavos, suprimiendo con ello toda la buena voluntad que las naciones distantes tenían hacia Estados Unidos. Parker declaró en junio de 1846:

Considero que la presente guerra, aunque puede costar 50000 hombres y 50000000 de dólares es la parte más pequeña de nuestro infortunio. iEn el exterior se nos considera una nación de estafadores y ladrones! ¿Qué podemos decir en nuestra defensa? La nación traiciona su gran ideal: todos los hombres nacen iguales, cada uno con los mismos derechos inalienables. Somos infieles a la cristiandad. Hemos pagado el costo de nuestra vergüenza. ${ }^{8}$

Igualmente la American Peace Society, con base en Boston, identificaba la es-

${ }^{8}$ Schroeder, Polk, 1973, p. 105; Mayer, Fire, 1998, pp. 360-361; Parker, Sermon, 1846, p. 41. 
clavitud como el móvil principal de la guerra, y advertía contra un posible conquistador Napoleón estadunidense. Éste podría lanzar sus legiones contra Estados Unidos después de México, y luego establecerse como su presidente perpetuo.?

Menos lúgubre que la tendencia de Thoreau-Garrison-Parker, pero igualmente apasionada, fue la protesta que hizo James Russell Lowell. Este vástago de una distinguida familia de Massachusetts escribió versos satíricos en su popular $B i$ glow Papers. En ellos presentaba al aldeano de Nueva Inglaterra Hosea Biglow. Percibía claramente lo que se escondía atrás de la grandilocuencia. La charla patriótica de Polk no le ocultó la realidad de que toda guerra llega a ser una carnicería autorizada. Llamaba a la política de Polk hacia México una operación de piratería para crear "rediles más grandes para llenar de esclavos". ${ }^{10}$

Los abolicionistas, los clérigos liberales y otros seres sensibles no monopolizaron las objeciones. El descontento también se extendió al ejército. Ulysses S. Grant, quien prestaba servicio como oficial subalterno en la guerra, se refirió a ella más tarde como una causa indefendible: "una de las más injustas [guerras] nunca librada por una nación más fuerte contra una más débil". Más de 9200 hombres uniformados desertaron de sus unidades. Varios de los desertores se unieron a las filas enemigas. El infausto batallón de San Patricio de Santa Anna estaba compuesto por estadunidenses descontentos -algunos irlandeses, muchos católicos, dirigidos por

${ }^{9}$ Livermore, War, 1850 , p. 14; Schroeder, Polk, 1973 , pp. 94-95. Véase también el estudio de Moody, Facts, 1971.

${ }^{10}$ Wortham, James, 1977, p. 53.
John Riley, originario de Galway- que habían abandonado el ejército de Estados Unidos para unirse al de México. ${ }^{11}$

Los miembros mayores de la clase responsable, y alguna vez de la rama ejecutiva, también se quejaron. Joel Poinsett, antiguo ministro en México (1825-1829), así como miembro del Congreso (18211825) y secretario de Guerra (1837-1841), se lamentó del conflicto que se libraba entre regímenes republicanos fraternos. La invasión y la conquista ayudarían materialmente a los reaccionarios mexicanos, decía; éstos han buscado desde hace mucho tiempo extirpar los tiernos brotes de democracia que aparecieron en 1824. Era triste que Polk diera a los reaccionarios un pretexto para socavar todavía más a los acosados liberales de México. Waddy Thompson, otro enviado a México (18421844), abogaba por una diplomacia más paciente. Juzgaba la guerra imprudente, ya que negaba a Washington un futuro aliado mexicano contra las intrigas europeas en América. ${ }^{12} \mathrm{El}$ anciano Albert Gallatin, secretario del Tesoro bajo Thomas Jefferson, advirtió contra la corrupción de la virtud republicana que se requería en cualquier empresa imperialista. Sus compatriotas estaban en peligro de abandonar a sus mejores ángeles, escribió en panfletos ampliamente publicados y leídos en 1847: Peace with Mexico y War Expenses. El irredento mundo, todavía mirando esperanzado a Estados Unidos, iba sufrir si el país sucumbía a ambiciones atávicas.

${ }^{11}$ U.S. Grant, Personal, 1996, vol. I, p. 37; Miller, Shamrack, 1989, pp. 111-112; Eisenhower, So Far, 1989 , p. XVII; McEniry, American, 1937, pp. 73-98.

${ }^{12}$ Lander, Reluctant, 1980, pp. 23, 67; Johannsen, Halls, 1985, pp. 294-295; Rippy, Joel, 1968 , pp. 226-230. 
Vuestra misión era ser un modelo para los demás gobiernos y para todas las otras naciones menos favorecidas, para que se adhirieran a los más elevados principios de moralidad política, para aplicar todas vuestras facultades a la mejora gradual de vuestras instituciones y estado social, y con vuestro ejemplo ejercer una influencia moral más benéfica a largo plazo para la humanidad. En vez de esto, se ha hecho un llamado a vuestras peores pasiones; a la codicia; a la sed de injusto engrandecimiento por la fuerza bruta; al amor de la fama militar y de la gloria falsa; y se ha intentado pervertir los sentimientos más nobles de vuestra naturaleza. Se intenta que abandonéis la elevada posición que vuestros padres ocuparon, para sustituirla con la moralidad política y el pagano patriotismo de los héroes y estadistas de la antigüedad. ${ }^{13}$

Los demócratas de Polk y quienes los apoyaban en la prensa desecharon este desacuerdo. Se decía que Gallatin era un vejestorio. Acogía simpatías extranjeras. Sus gustos eran cosmopolitas, no verdaderamente estadunidenses. Igualmente Poinsett y Thompson no estaban al corriente de los sentimientos prevalecientes. Los extremistas de Massachusetts sólo se representaban a ellos mismos. Todos los disidentes, intencionalmente o no, alentaban la resistencia mexicana. Se acercaban peligrosamente a la traición, acusó un exasperado Polk. Fracasaban en comprender lo saludable de la causa de la nación. Fortificaban al enemigo con "ayuda y consuelo," diferente en grado de la pan-

${ }^{1.3}$ Hunt, Ideology, 1987, p. 34; Horsman, Race, 1981, pp. 269-270; "Peace with Mexico" en Ferguson, Selected, 1967, p. 486. dilla de San Patricio, pero del mismo tipo. ${ }^{14}$

\section{CONQUISTA}

En 1846 México cumplía justamente 25 años de haber abandonado al gobierno colonial de Madrid. La guerra de liberación contra España había sido abrumado$\mathrm{ra}$, brevemente repetida en la desatinada reconquista de 1829 (frustrada por los éxitos de Santa Anna en el campo de bata1la). Durante el primer cuarto de siglo del México libre se dio una serie de crisis que asolaron la nación, provocadas por la incertidumbre económico-política, los antagonismos de clase y las enemistades raciales.

Subían las deudas públicas y privadas. La propiedad de las minas del país, el elemento más productivo en la economía mexicana, caía en manos extranjeras. ${ }^{15}$ Las indemnizaciones reclamadas por ciudadanos franceses, ingleses y estaduniclenses por daños a sus propiedades durante los desórdenes mexicanos alcanzaban proporciones alarmantes (más de 2000000 de dólares en el caso estadunidense). La rivalidad entre las autoridades federales y estatales aumentaba la debilidad política. Las revoluciones palaciegas y las elecciones impugnadas aceleraban el ritmo de las caídas de gobiernos. Entre la abortada reconquista y la elección estadunidense de 1884 que ganó Polk, la presidencia

${ }^{14}$ Merk, Manifest, 1963 , p. 185 ; Second Annual Message de Polk, 8 de diciembre de 1846 en $\mathrm{Ri-}$ chardson, Messages, 1897, vol. v, p. 2323; Smith, War, 1919, vol. II, pp. 280-281.

${ }^{15}$ Schoultz, Beneath, 1998 , p. 14. 
mexicana había cambiado de manos 20 veces; catorce hombres diferentes tuvieron el puesto ejecutivo. ${ }^{16} \mathrm{El}$ ejército era el actor más influyente en la política nacional. Estaba dirigido por criollos privilegiados. Mandaban tropas indígenas pobremente adiestradas que no poseían ni identidad nacional ni fidelidad. La sintomática debilidad mexicana era la ausencia relativa de apoyo público en la guerra del gobierno contra los invasores estadunidenses (particularmente en provincias lejanas al centro, como California). ${ }^{17}$ México, en el momento de la mayor crisis de seguridad desde Cortés, se calificaba -en lenguaje contemporáneo- como un Estado fallido.

La colisión mexicano-estadunidense de 1846 coronaba una historia descorazonadora. Washington había reconocido sin demora la independencia mexicana en 1821. Pero ningún enviado de Estados Unidos presentó credenciales hasta 1825. El antiguo ministro Poinsett se hizo impopular con sus anfitriones entremetiéndose en asuntos domésticos. Intentó con torpeza promover instituciones políticas al estilo de Estados Unidos. Washington lo mandó llamar a pedido del ministro de Asuntos Extranjeros de México. Entre tanto, dos presidentes, John Quincy Adams y Andrew Jackson, buscaron obtener todo -0 partes- de Texas. Este proyecto topó con el rechazo mexicano. La iniciativa Adams-Jackson despertó también sospechas de aspiraciones a largo plazo de Estados Unidos. En consecuencia, los funcionarios mexicanos dieron pasos para reducir la inmigración de estadunidenses a Texas y asimilar a los protestantes

${ }^{16}$ Brack, Mexico, 1975, pp. 53-54.

${ }^{17}$ Weber, Mexican, 1982, pp. 275-276. de habla inglesa ya existentes. Se esperaba que se convirtieran al catolicismo romano, acatando la prohibición de la esclavitud del presidente Vicente Guerrero de 1829 y, por lo demás, se sujetaran a las costumbres y leyes locales.

El número de colonos angloamericanos, originalmente dirigidos por Stephen F. Austin en los años 1820, excedía los 20000 al momento en que estalló la revolución de Texas en 1835 . Superaban a los mexicanos locales, según diferentes estimaciones que oscilaban entre siete a uno y diez a uno. ${ }^{18}$ Los dueños de esclavos entre los colonos mantuvieron su propiedad: 2000 almas. La mayoría de los inmigrantes conservaron su fe en la religión protestante. La determinación de Santa Anna de mantener el mandato de la ciudad de México en Texas, en tanto que se desmantelaba la constitución republicana, precipitó el levantamiento angloamericano. [Éste] gozó de apoyo popular en Estados Unidos. Contribuciones privadas de hombres y de material se vertieron en Texas. El horror estadunidense por la crueldad mexicana en El Álamo y Goliad (en donde Santa Anna ordenó asesinar a 445 prisioneros) era palpablemente fuerte. Era patente entre las autoridades el gozo por la derrota y captura de Santa Anna en San Jacinto por el ejército de Sam Houston, en abril de 1836. Esas demostraciones de sentimientos se resentían en la ciudad de México, a pesar de las afirmaciones del presidente Jackson sobre la neutralidad de Estados Unidos y la decisión de impedir a Texas la entrada a la Unión.

${ }^{18}$ Beard, Basic, 1960, p. 186; McDougall, Promised, 1997, p. 90. 
Los retrasos subsecuentes en la admisión se derivaban de esta preocupación norteña: el dar cabida a otro estado esclavista restaría balance al equilibrio regional-político de la Unión. Cuando el Congreso finalmente se ablandó y admitió a Texas -en parte para impedir la injerencia británica- el gobierno federal adoptó como propio el antiguo reclamo de Texas: esto es, la frontera sur de Texas a lo largo del río Grande, 150 millas más abajo de la línea impuesta por los mexicanos correspondiente al tío Nueces. ${ }^{19}$ La psicología de Texas de resentimiento contra México, alimentada por escaramuzas fronterizas durante los años de la república de la Estrella Solitaria, pasó también sutilmente a la oficialidad de Estados Unidos.

Mientras tanto, abajo de la frontera se arraigó la yanquifobia, nacida del papel que se presumía había tenido Washington en la consiguiente independencia de Texas en 1836-1845. Apareció cada vez más preocupación por el destino de los escasamente poblados límites fronterizos que quedaban cerca de los inquietos estadunidenses. Bajo la impresión equivocada de que México y Estados Unidos habían declarado la guerra, el comodoro Thomas Jones utilizó sus barcos de guerra y marinos para capturar la capital provincial de California (Monterey) en octubre de 1842. A pesar del vergonzoso error, la acción de Jones demostró la vulnerabilidad de las provincias remotas. Este episodio sirvió también para confirmar la tendencia de Estados Unidos a actos violentos. Agravando el asunto, muchos mexicanos esclarecidos, intelectuales y políticas injuriaron a Estados Unidos como una cultura no desarrollada. Permitía la escla-

\footnotetext{
${ }^{19}$ Iriye, Nationalism, 1977, p. 33.
}

vitud, la poligamia (los mormones), el ateísmo, y era de otras maneras primitivo. ${ }^{20}$ Tales nociones eran paralelas al desprecio de México como racialmente inferior, políticamente inadecuado, dirigido por sacerdotes y sumido en la superstición. Bajo este punto de vista, la animosidad entre el protestantismo de habla inglesa y el catolicismo de habla castellana en Europa -más viejo que la Armadaalimentó la confrontación México-Estados Unidos. El senador John C. Calhoun sostuvo (en diciembre de 1846) que Estados Unidos había cometido el error de las hostilidades, cuya intensidad provenía de una antigua antipatía entre tazas y credos incompatibles. Predijo que este choque de civilizaciones sólo "terminaría con el sometimiento completo de la potencia más débil -algo que no fácilmente se lograba". ${ }^{21}$

El fracaso, en marzo de 1846 , de la diligencia de John Slidell en la ciudad de México para negociar con el gobierno de José Herrera -determinar los reclamos de Estados Unidos por daños, comprar Nuevo México y California y obtener reconocimiento de la frontera del río Grande para Texas- fue la causa inmediata de las hostilidades. Esta misión, enviada en noviembre de 1845 , nunca tuvo muchas oportunidades de ser exitosa. No era posible que el vacilante gobierno de Herrera hubiese resistido las críticas que seguramente surgirían por aplacar a los codiciosos estadunidenses. Ciertamente, a pesar

${ }^{20}$ Robinson, View, 1989, p. xxiv, 195; Chaney, "Mexican", 1959, p. 2; Brack, Mexico, 1975, pp. 11, 170.

${ }^{21}$ Calhoun a Anna Maria Calhoun Clemson, 27 de diciembre de 1846 en Wilson y Cook, Papers, 1998, vol. XxIv, pp. 42-44. 
de la negativa de Herrera de reunirse con Slidell, el gobierno cayó fácilmente en un golpe (diciembre de 1845) dirigido por el general Mariano Paredes, quien acusó a Herrera de tener intenciones traicioneras de entregar el norte de México. Paredes estaba aún menos dispuesto que su predecesor a negociar con Slidell, y provocó lo que al final resultaron ser ilusiones de las habilidades militares de México. Creía que sus fuerzas vapulearían a los estadunidenses que habían dado una débil demostración contra Gran Bretaña en 1812. México lo había hecho bien en el pasado reciente: contra España, contra Francia en 1838 (guerra de los Pasteles). ${ }^{22}$ Más aún, México podía esperar una mediación amistosa de parte de Inglaterra, y quizá hasta su colaboración militar contra Estados Unidos. En cualquier caso, con mayor evidencia se sugiere que Polk anticipó el fracaso de la misión de Slidell, que había sido armada por la necesidad de tener pretexto para empezar las hostilidades. Supuso que éstas iban a ser de corta duración o quizá ni siquiera entabladas. ${ }^{23}$ Los problemas políticos de México, las desventajas financieras y las deficiencias militares - grandes ejércitos pero mal equipados y divididos políticamente- disuadirían a Herrera, a Paredes o a cualquier otro de enredarse con Estados Unidos. Coincidiendo con la acción de Slidell, Polk había asignado (en enero de 1846) al ejército de ocupación de Texas del general Zachary Taylor 4000 soldados para asegurar el control del territorio disputado arriba del río Grande. Este ejército marchó de Corpus Christi hacia la ribera izquierda del

\footnotetext{
${ }^{22}$ Chaney, "Mexican", 1959, pp. 12-15; Robinson, View, 1989, p. XxvII.

${ }^{23}$ Weber, Mexican, 1982, p. 274.
}

río y estableció ahí Fort Texas, al lado opuesto de la ciudad de Matamoros, que protegía la guarnición del general Francisco Mejía.

La acción de Taylor fue interpretada en México como una franca agresión. La emboscada a la patrulla del capitán Seth Thornton (abril de 1846) por la caballería mexicana que previamente había cruzado la orilla izquierda fue el primer acto violento. A continuación Taylor reportó a Washington que las hostilidades se habían iniciado por iniciativa mexicana. Se realizaron batallas a principios de mayo entre el ejército de Taylor y los mexicanos, numéricamente superiores, y los últimos fueron derrotados en Palo Alto y en Resaca de la Palma. Buscando de cualquier forma una declaración de guerra basada en reclamaciones no saldadas y en el rechazo a Slidell, Polk se animó al enterarse del contratiempo de Thorton. Reportó a la Cámara y al Senado (el 11 de mayo de 1846) que la sangre estadunidense había sido derramada en territorio estadunidense por intrusos. "La copa de tolerancia", suspiró, "se ha agotado [...] Tras repetidas amenazas, México ha cruzado la frontera de Estados Unidos y ha invadido nuestro territorio." 24

Polk no solicitó al Congreso una declaración formal de guerra. En vez de ello pidió a los legisladores reconocer que un estado de beligerancia ya estaba presente -"por circunlocución, una declaración de guerra con México" (frase de John Quincy Adams). ${ }^{25} \mathrm{El}$ deber del Congreso era ayu-

${ }^{24}$ Polk al Senado y a la Cámara de Representantes, 11 de mayo de 1846 en Richardson, Messager, 1897, vol. v, p. 2292.

${ }^{25}$ Entrada del 11 de mayo de 1846 en Adams, Memoirs, 1877, vol. XI, p. 261. 
dar a las tropas de Taylor, que se creía estaban bajo la amenaza de un ataque mexicano fulminante, autorizando al ejecutivo a enlistar voluntarios (50 000 hombres) y comprar municiones, además de otros abastos (con valor de 10000000 de dólares). Ambas cámaras sostuvieron breves debates. Los hombres de Polk los dominaron. En el Senado sólo dos wbigs votaron contra el presidente: John Davis de Massachusetts y John Clayton de Delaware. La lealtad al Partido Demócrata impidió que Calhoun votara en contra de la declaración de guerra de Polk. Se abstuvo. De todas maneras, consideró que las deliberaciones del Senado habían sido apresuradas; habían sido una estampida dirigida por Polk. Le preocupaba también que el presidente había usurpado la autoridad del Congreso para hacer la guerra; ésta sólo podía iniciarse cuando el Congreso comprometía a la nación por medio de una declaración solemne. Lewis Cass, de Michigan, replicó que los eventos sangrientos producen la guerra, no el pronunciamiento de los legisladores:

Por mi parte, consideraré las hostilidades públicas como guerra, dándonos todos los derechos que esa condición conlleva -el derecho de expulsar a nuestro enemigo de nuestro suelo, y seguirlo a dondequiera que vaya, hasta conquistarlo y llevarlo a un estado de paz. ${ }^{26}$

Sólo catorce miembros de la Cámara (todos ellos whigs), dirigidos por John Quincy Adams, votaron en contra de que Polk obtuviera hombres y equipo. Una mayoría bipartidista prefirió no examinar el argumento de Polk de que México ha-

${ }^{26}$ Congressional Globe, Appendix, 1846, p. 646. bía montado una invasión a territorio estadunidense. Este razonamiento de Jacob Brinkerhoff de Ohio sostenía:

Es suficiente para mí, como hombre que profesa una parte ordinaria de patriotismo y representa a un grupo patriótico, saber que [la guerra] existe [...] Nuestro único camino es conquistar la paz con un vigoroso proseguimiento de la guerra que se ha iniciado. Si la guerra de 1812 dio una lección a ésta o a cualquier otra nación, es una tontería, una locura proseguir con una guerra insignificante. No estoy a favor de una guerra así. Estoy a favor de continuar esta guerra de tal manera que nuestros enemigos sean de inmediato aplastados -una guerra que deba ponerlos a nuestros pies, por completo y al instante, y obligarlos a pactar una paz honorable. ${ }^{27}$

Al desarrollarse la guerra se produjo una cadena de victorias de Estados Unidos, sin contar la alta tasa de muertes estadunidenses, atribuidas principalmente a enfermedades: cólera, disentería y fiebre amarilla. (En conjunto murieron 13768 hombres de un ejército regular de voluntarios de 104 566.) En el mar dominaba la armada. México no poseía un auténtico poderío bélico marítimo. La marina impuso fuertes bloqueos a los puertos mexicanos. Llevó a cabo efectivas operaciones de combate logístico en el Golfo, notoriamente en cooperación con el ataque anfibio de Winfield Scott a Veracruz en mayo de 1847. La marina desempeñó también un papel de acoso, en la costa del Pacífico, que contribuyó a la captura de California. Las operaciones terrestres se iniciaron en el norte de México, en donde el ejército

${ }^{27}$ Congressional Globe, First, 1846, p. 792. 
de Taylor se abrió paso en varios estados mexicanos: Tamaulipas, Nuevo León y Coahuila. El éxito del ejército en la batalla de Buena Vista, en febrero de 1847, afirmó la fama de Taylor e impulsó al soldado políticamente neutral (nominalmente un whig) hacia la Casa Blanca. El ejército occidental del general Stephen Kearny (de 1700 hombres) capturó en agosto de 1846 la capital de Nuevo México, Santa $\mathrm{Fe}$, con mínimo derramamiento de sangre. Más adelante, una parte de ese rudo ejército, dirigido por Kearny, marchó a California, llegando a San Diego en diciembre de 1846. A continuación se vio enredado en las disputas políticas de la California ocupada, una opera bouffe en grande. (Ello culminó con el consejo de guerra del capitán John C. Fremont y un embrollo que consumió al suegro de Fremont, el senador Thomas Hart Benton.) En lo referente a la campaña del general Scott en el corazón de México: su sucesión de astutas maniobras y batallas duramente peleadas, siguiendo la ruta de la invasión de Cortés en el siglo XVI, terminó con la captura de la capital en septiembre de 1847. La imaginación de numerosos estadunidenses había sido incitada al leer el relato de 1843 de William Hickling Prescott sobre la expedición de Cortés: History of the Conquest of Mexico. Estaban entusiasmados por las hazañas de los aventureros de los últimos días, cuyos triunfos parecían haber estado predichos en el relato de Prescott. El rudo duque de Wellington se encontraba entre esos observadores extranjeros que alabaron a Scott como la figura militar preeminente de su época. ${ }^{28}$

${ }^{28}$ Einsenhower, So Far, 1989, pp. xviI, xxv; Stephanson, Manifest, 1995, p. 37; Bauer, Mexican, 1974, pp. XIX, 374, 395; Saul, Distant, 1991, p. 173.
Este éxito de Estados Unidos se logró a pesar de serios obstáculos. Éstos comprendieron peculado, además de desperdicio en la producción y adquisición durante la guerra. Las instancias de notable indisciplina entre las unidades de voluntarios entorpecieron el esfuerzo militar. Los turbulentos Texas Rangers cometieron un número desproporcionado de atrocidades reportadas sobre civiles mexicanos: pillajes, violaciones, fusilamientos y escalpaciones. Los generales Taylor y Scott estaban indignados. Periódicamente lanzaban su ira contra los Rangers. Sin embargo, éstos fueron conservados por sus habilidades como guías y por su efectividad contra guerrillas merodeadoras. Potencialmente el mayor obstáculo para la victoria surgió de la complejidad entre civiles y militares: celos entre los comandantes de campo (Taylor contra Scott, William Worth contra Scott); la enfermiza sospecha y aversión hacia Taylor y Scott (ambos whigs) por parte de Polk; la determinación del presidente de mitigar el atractivo popular de sus dos principales generales y reducir su indecorosa preeminencia. En un punto, Polk esperaba nombrar a Benton teniente general, por lo tanto, dándole un grado mayor que el de Taylor y Scott, ambos sólo generales de división. Polk también esperaba contener a Scott por medio del torpemente ambicioso general Gideon Pillow, un incompetente aficionado que debía su grado exclusivamente a favores políticos. Éste se convirtió en el punto focal de una cábala de oficiales anti Scott. La conspiración de Pillow contra Scott dio como resultado un embrollo de investigaciones oficiales y consejos de guerra. Ello llevó al retiro de Scott del mando en enero de 1848. El general William Orlando Butler lo sustitu- 
yó con órdenes de presidir el inconcluso asunto de las negociaciones del tratado. George Meade, quien sirvió como joven teniente en los ejércitos de Taylor y de Scott, concluyó que Estados Unidos había sido bendecido al tener como enemigo a México: "Si hubiese sido cualquier otra potencia, nuestras enormes tonterías hubiesen sido castigadas con severidad." 29

La resistencia mexicana a la invasión fue obstinada, aunque sin posibilidad de victoria. Santa Anna no podía montar operaciones de ofensiva fuertes. Pero era astuto, porfiado en engañar a la administración de Polk. Esto le permitió recibir las fianzas apropiadas en su exilio en La Habana para volver a México -sin la interferencia de un bloqueo de barcos estadunidenses- para organizar un nuevo gobierno. Era de presumir que esto cesaría las hostilidades. Podría ofrecer generosos términos a Polk. En vez de ello, Santa Anna reunió un ejército apenas hubo regresado a México, en agosto de 1846. Inmediatamente partió con sus tropas a enfrentarse a las fuerzas de Taylor en Buena Vista. A partir de ahí intentó reducir las embestidas de Scott, dejando estas futilidades sólo después de que los estadunidenses tomaron la ciudad de México -lo cual provocó que Santa Anna renunciara a la presidencia a favor de Pedro María de Anaya y huyera nuevamente al exilio en Jamaica.

Uno de los efectos de esta obstinación mexicana fue el surgimiento en Estados Unidos del movimiento "Todo México". ${ }^{30}$

${ }^{29}$ DeVoto, Year, 1943, p. 278; Scott, Memoirs, 1864, vol. II, pp. 392-396; Otis, Mexican, 1960, pp. 144-147; Haynes, James, 1997, pp. 152-153, 174.

${ }^{30}$ Fuller, Movement, 1936, pp. 49, 79; Bauer, Mexican, 1974, p. 368.
Éste combinaba castigo con ambición desbordada. Asociado a los demócratas prominentes, este movimiento buscaba la anexión del país latino completo. El grupo "Todo México" incluía al secretario del Tesoro Robert Walker, al vicepresidente George Dallas, al secretario de Estado James Buchanan, Cass, y al senador de Illinois Stephen Douglas. El comodoro Robert Stockton, veterano de la conquista de California, apoyó este punto de vista cuando dijo en enero de 1848 a los ciudadanos de Filadelfia que expresaban su aprobación:

Si yo fuese ahora la autoridad soberana [...] proseguiría la guerra con el propósito expreso de redimir a México del mal gobierno y de la refriega civil [...] Con mano magnánima y bondadosa acogería a este desdichado pueblo en los pliegues del republicanismo. Esto lo haría a cualquier costo. ${ }^{31}$

Los opositores a la guerra replicaron: cualquier costo proyectado para reformar a 7000000 de mexicanos a imagen de Estados Unidos era demasiado fantástico para considerarlo con seriedad.

\section{OBJECIONES DEL CONGRESO}

Las disputas en el Congreso sobre los méritos de la guerra no únicamente separaron a los dos partidos. El desacuerdo también cavó zanjas en cada uno. Los whigs se dividieron entre ellos. Igual hicieron los demócratas. Las alianzas bipartidistas se formaron según las diversas preferencias entre los individuos. Las regiones entraron también en conflicto. No todos los norte-

${ }^{31}$ McDougall, Promised, 1997, p. 95. 


\section{SECUENCIG}

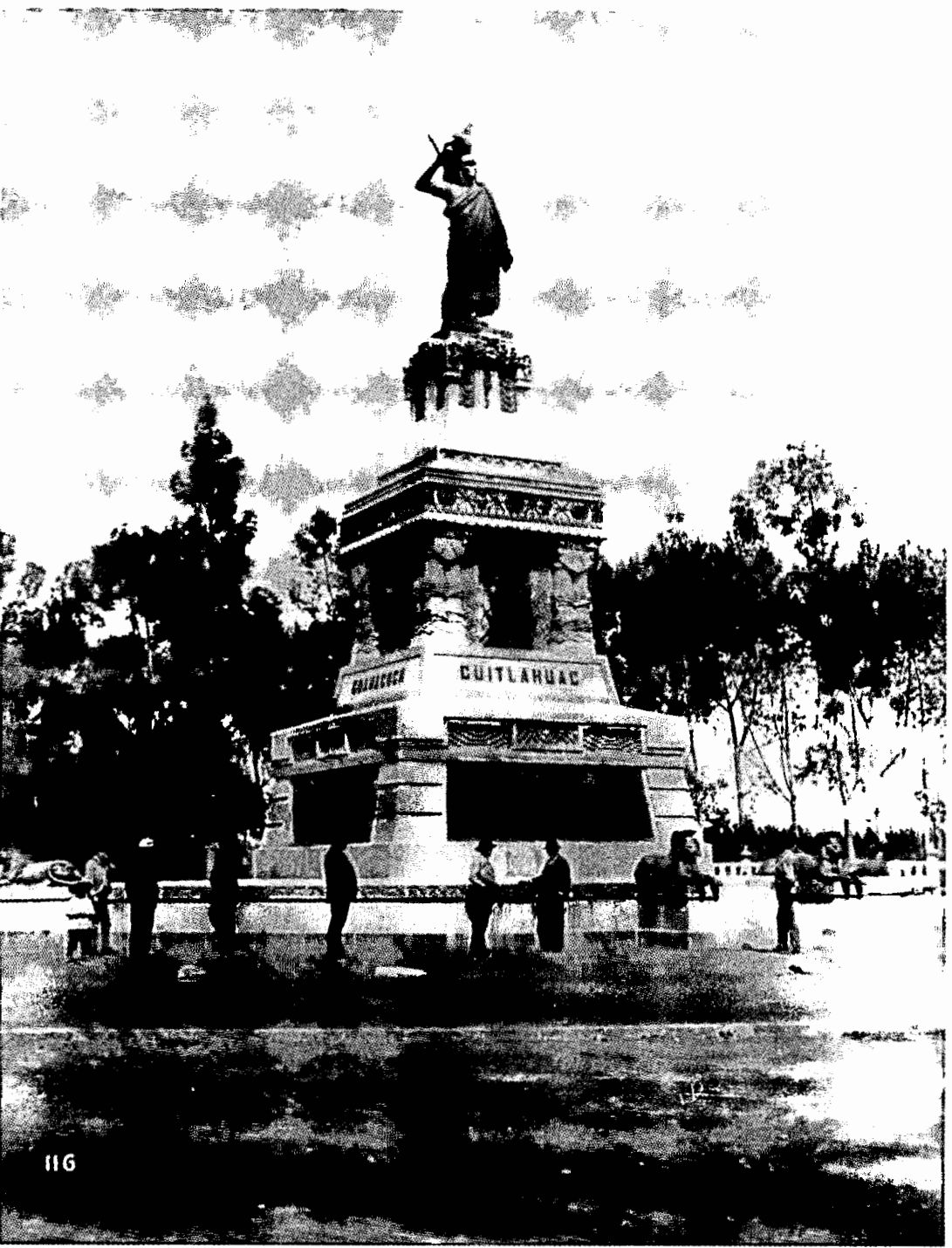


ños se oponían a la política de Polk. No todos los occidentales la aprobaban. El disentimiento simplemente no respetaba las líneas de división entre partidos y secciones. Entre los muchos legisladores que atacaron la política de Polk, dos se dibujaron con mayor dramatismo: el abolicionista whig de Ohio, el representante Joshua Giddings, y el elocuente apologista a favor de prerrogativas para el Sur, el senador Calhoun, de Carolina del Sur. Polk contrastaba débilmente con la vitalidad intelectual de estos dos hombres, nunca más que cuando aseguraba que la cuestión de la extensión de la esclavitud a las antiguas propiedades mexicanas no debía distraer a los estadunidenses. La cuestión debía considerarse como meramente "abstracta", no "práctica" ni de preocupación inmediata: "La esclavitud no tiene conexión posible con la guerra con México."32

Polk era un presidente por accidente. Su victoria ante Henry Clay en 1844 había sido por un estrecho margen. Antes de eso, la carrera política de Polk casi se había difuminado. Polk había servido al Congreso durante siete periodos, empezando en 1825 . Se convirtió en vocero de la Asamblea en 1835, cuando logró alguna reputación por sus laboriosas diligencias. A continuación ganó como gobernador de Tennessee en 1839. Pero perdió la reelección en 1841 . Volvió a ser derrotado en la carrera por el puesto en 1844. Su única virtud reconocida era la lealtad a Andrew Jackson y su filosofía pública, que le ganó a Polk el sobrenombre del "Joven Hickory". Su escasez de atractivo personal y su tendencia al secreto no lo congraciaban con muchos dentro

${ }^{32}$ Entrada del 5 de enero de 1847 en Quaife, Diary, 1910, vol. II, p. 308. de su propio partido. Calhoun no podía resistir su superficialidad intelectual (o que ocupara la mansión ejecutiva en vez de la de Carolina del Sur). A los demócratas del Norte de la clase de Van Buren -los barnburners - no les gustaba Polk, al que tachaban de dueño de esclavos y apologista. La pérdida demócrata de la mayoría de la Asamblea en las elecciones de medio periodo de 1846 fue el resultado, en parte, de la inhabilidad de Polk para armonizar las discordias del partido (además de los resentimientos por el veto del presidente al decreto de ríos y puertos; la aprobación de la Tarifa Walker, que ofendió a los proteccionistas, y el establecimiento de un tesoro independiente que consternó a los conservadores financieros). La continuación de una guerra al parecer sin un posible término también hacía daño. Ésta había prometido originalmente una ganancia sustancial con mínimo esfuerzo, no con los millones de dólares y los miles de hombres que Polk solicitaba. ${ }^{33}$

\section{WHIGS}

Abraham Lincoln, de Illinois, estaba entre los whigs elegidos al Congreso en 1846. El larguirucho occidental lanzó hirientes ataques al presidente luego de tomar posesión de su escaño en la Asamblea. Lincoln esperaba advertir con ellos las múltiples deficiencias de Polk y la ineptitud de los demócratas para gobernar. ${ }^{34}$ Nunca llegó tan lejos como el senador Daniel Webster cuando sugirió que Polk debía ser im-

\footnotetext{
${ }^{33}$ Schroeder, Polk, 1973, p. 57; Wiltse, Papers, 1984, vol. vI, p. 209; Haynes, James, 1997, p. 155; Richards, Life, 1986, p. 173.

${ }^{34}$ Donald, Lincoln, 1995, pp. 123-124, 126.
} 
pugnado. Pero Lincoln hizo ciertamente ver en su "anuncio" resoluciones (diciembre de 1847) para humillar al presidente. ¿Dónde se encontraba el prístino suelo estadunidense, preguntaba el congresista novato, que había sido violado por miserables invasores mexicanos, en donde se había derramado la sangre de inocentes estadunidenses? De hecho, respondía, el sitio en donde ocurrió la primera violencia había sido disputado desde hacía mucho, y pertenecía a la categoría de reclamaciones en disputa, sin certidumbre legal. Aún más, los habitantes de esa tierra nunca han estado sujetos a las leyes o a la protección de Estados Unidos. Además, la violencia se había cometido contra soldados armados; su presencia en el río Grande había sido comprensiblemente considerada por los mexicanos como una provocación. Con igual estridencia, Lincoln añadió más tarde, en enero de 1848 , que Polk había mentido para desencadenar una guerra evitable: "Percibe que la sangre de esta guerra, como la sangre de Abel, clama al Cielo en contra de él."35 Sólo la repugnancia de ver soldados heridos en el campo de batalla hizo que Lincoln votara repetidamente para proveerlos de material. Los whigs más disidentes adoptaron esta misma posición de apoyo al ejército, temiendo que si no se hacía así se verían como los federalistas de 1812 -derrotistas y desleales- y sufrirían el mismo destino: la extinción política.

Las críticas de Lincoln no hicieron mella: Polk ignoró las cuestiones acusato-

\footnotetext{
${ }^{35}$ Spot Resolutions in the U.S. House of Representatives, 22 de diciembre de 1847, y Speech in the U.S. House of Representatives on the War with Mexico, 12 de enero de 1848 en Fehrenbacher, Abrabam, 1989, pp. 158-159, 161-171.
}

rias. Nunca mencionó en su diario la temeridad de Lincoln, una omisión reveladora, ya que las memorias del presidente rebosan veneno para aquellos que lo molestaron. Tampoco se dignó Polk responder a otros molestos whigs como el talentoso Robert Toombs, de Georgia, cuando acusó al presidente de lanzar un ejército a México sin autorización de la ley. El legislador de Georgia tocó temas no muy diferentes de los de los habitantes de Nueva Inglaterra que atacaban a Polk.

La guerra en una causa justa es una gran calamidad para cualquier individuo [opinaba Toombs], y sólo puede justificarse por la más alta necesidad. Un pueblo que se lanza a la guerra sin una causa justa y suficiente, sin otro motivo que el orgullo y el deseo de gloria, es enemigo de la raza humana y merece el desprecio de toda la humanidad. ${ }^{36}$

Otro whig de Georgia de creciente fama, Alexander Stephens, llamó a la guerra una afrenta a la vida civilizada, una perversión de virtudes republicanas. Temía que la violencia de la guerra condujera a Estados Unidos a una espiral decadente.

Más difíciles de ignorar que Lincoln, Toombs o Stephens, eran para Polk los líderes whigs como Webster. Éste tenía la vista fija en una carrera presidencial en 1848. Esta ambición lo inhibía para decir cosas que pudieran alienar a los whigs sureños, que eran cruciales para obtener el nombramiento del partido. Éstos ya estaban asustados gracias a las acusaciones de una conspiración de guerra hechas por los partidarios de John Quincy Adams y

${ }^{36}$ Pleasant, Toombs, 1892 , pp. 53, 59-60; Schroeder, Polk, 1973, p. 28. 
Theodore Parker, que expresaban la integridad moral-política del Sur. En consecuencia, las afirmaciones públicas de Webster estaban de alguna manera suavizadas. Siendo un "whig de algodón", con una sobria apreciación de la importancia de la producción sureña para la industria textil norteña, Webster se sintió todavía más cohibido: nunca calificó a la guerra como vehículo para ampliar el cinturón esclavista. Pero, aun limitado por estas precauciones, era formidable. Execró la guerra. Afirmó que dependía de los fraudes e invenciones de Polk; éstos justificaban la impía agresión a los simples. Favorecía la propuesta presentada por el senador John Berrien de Georgia que prohibía la toma de cualquier nuevo territorio. Webster finalmente votó en contra del tratado de paz de 1848 por dos motivos. Era absurdamente duro. La última cosa que necesitaba Estados Unidos era tierra indigesta del cuerpo de México. ${ }^{37}$

Los whigs antiesclavistas estaban motivados por una convicción más profunda que la de animar un compañerismo ordinario a la Lincoln o a la Webster. Los "ultras" utilizaban todo artilugio para parar o revertir la guerra de Polk. Las principales figuras de esta facción fueron Adams -quejumbroso e insistente-y su lugarteniente, Giddings. Ellos combinaban el ardor de cruzados con el ultraje. Adams, con su posición de eminence grise, dio a esta ruidosa minoría un aura de credibilidad. $\mathrm{Al}$ deteriorarse la salud de Adams, Gid-

37 "The Mexican War", 1 de marzo de 1847 y "Objects of the Mexican War", 23 de marzo de 1848 en Wiltse, Papers, 1988, pp. 435-445, 447-476; entrada del 3 de marzo de 1848 en Quaife, Diary, 1910, vol. III, pp. 370-371. dings adquirió el liderazgo de los radicales. Adams era efectivamente la cabeza titular, Giddings, el espíritu. Para ellos la maldad de la guerra agresiva de Polk sólo era superada por el propósito supuesto: ampliar la zona de esclavitud. Adams esperaba que los soldados estadunidenses desertaran antes que prestarse a este objetivo sin atractivo. Respecto a Polk, alguna vez soltó que era un "poseedor de esclavos exterminador de indios", difícilmente calificado para ser abogado en un juzgado de distrito. ${ }^{38}$

Debilitado por las enfermedades, además de los efectos de la apoplejía, Adams confió a Giddings promover lo justo. Actuó en beneficio de la sensibilidad de Nueva Inglaterra en la Reserva Occidental de Ohio, originalmente poblada con emigrantes de Connecticut. Representó esta distinguida región durante dos décadas en el Congreso (1838-1859). Como muchos otros en este distrito electoral, era congregacionalista, y estaba muy influenciado por la teología del Segundo Gran Despertar (Second Great Awakening). Aceptó como principio doctrinal el imperativo de trabajar por la mejora de la sociedad. De entre los males que afectaban a Estados Unidos, ninguno, desde su punto de vista, superaba al de la esclavitud. Su hogar no estaba lejos del centro abolicionista-congregacionalista en Oberlin. Sostuvo su sentido de misión y lo reforzó durante épocas difíciles. Éstas incluyeron haber sido censurado por la Cámara baja del Congreso en 1842 por atacar con rudeza a la institución de la esclavitud.

\footnotetext{
${ }^{38}$ Morison, Merk y Freidel, Dissent, 1970, pp. 42; Stephanson, Manifest, 1995, p. 34; Richards, Life, 1986, pp. 182, 188 y 190.
} 
En palabras de la moción patrocinadora, había traicionado la confianza pública creando mucha "agitación, insatisfacción y división". Los dueños de esclavos lo describían como implacable y "rabioso". No pocos historiadores han acusado a Giddings de haber fallado. Justin Smith, un importante cronista de la guerra con México a principios del siglo Xx, calificó a Giddings de "fanático calculador". 39

Sin embargo, para sus amigos era un personaje heroico cuya corpulencia y naturaleza robusta -seis pies dos pulgadas, 200 libras, coronadas por una melena rubia- lo ayudaron a soportar burlas y amenazas de daño físico por sureños exaltados. Había sobrevivido al servicio militar en la guerra de 1812. Había superado ataques de depresión para establecer una próspera práctica de leyes. Su optimismo esencial alimentó su confianza en que todo mundo era capaz de percibir la verdad, especialmente en la forma en que él la veía: por ello sus ataques contra la empobrecida imaginación moral de la casta poseedora de esclavos. Su ansia de actividad lo hizo incansable en los cuerpos antiesclavistas. Cuestionó la legitimidad de los mercados de esclavos en el distrito de Columbia. Pidió que se investigaran las tasas de suicidios entre los esclavos en espera de subasta en la capital nacional. Ridiculizó la engañosa ciencia citada por Calhoun para apoyar el informe de que la esclavitud beneficiaba la salud mental-física-moral de los africanos. La apología sureña se apoyaba en una biología politizada y textos

${ }^{39}$ Stewart, Joshua, 1970, pp. 73-74; Alfred Aldrich a Calhoun, 21 de septiembre de 1847 en Wilson y Cook, Papers, 1998, vol. xxIv, p. 568; Smith, War, 1919, vol. II, p. 496, núm. 24. bíblicos malinterpretados, se burlaba Giddings. Entre los abolicionistas jóvenes y viejos, de Adams al fogoso Charles Summer (n. 1811), Giddings era reconocido como "maestro de todos nosotros en asuntos antiesclavistas". 40

Giddings coincidía con otros disidentes en que la guerra con México se burlaba de la Constitución. Según la pauta de ese documento, la política de Polk carecía de legalidad. Añadía que la guerra había disuelto efectivamente la Unión original, dejando en su lugar algo vulgar. ${ }^{41}$

Declaró en mayo de 1846 que esa precipitación a la violencia traicionó a los fundadores de Norteamérica -la línea Gallatin-, quienes nunca soñaron que sus descendientes se envenenarían con el amor por la vida militar o se movilizarían para infligir devastación a vecinos apacibles:

Esta guerra se dirige contra un pueblo inofensivo, sin una causa justa o adecuada, con el propósito de conquista; con la intención de extender la esclavitud; en violación de la Constitución; contra los dictados de la justicia, la humanidad, los sentimientos de la época en la que vivimos, y los preceptos de la religión que profesamos. ${ }^{42}$

Giddings no bromeaba cuando prometía oponerse a las pródigas y duras justificaciones de Polk a la guerra. Éstas lle-

${ }^{40}$ Stewart, Joshua, 1970, pp. 73-74; Alfred Aldrich a Calhoun, 21 de septiembre de 1847 en Wilson y Cook, Papers, 1998, vol. xxiv, p. 568; Smith, War, 1919, vol. II, p. 496, núm. 24.

${ }^{41}$ Mayer, Fire, 1998, p. 361; "Mexican War", 14 de julio de 1846 en Giddings, Speecher, 1968, pp. 250-264.

42 "The Mexican War", 12 de mayo de 1846 en Giddings, Speeches, 1968, pp. 177-201. 
gaban a la sofistería. No podían ocultar los hechos llanos: la administración había desatado una "ola de crimen" que producía miseria en los niños, mujeres y familias de México. Esta maldad prometía un terrible ajuste de cuentas para Estados Unidos, decía Giddings. Para él, como para muchos moralistas de su tiempo, Dios estaba íntimamente involucrado en los asuntos humanos, administrando castigo o salvación según las obras:

La historia del mundo muestra que los crímenes nacionales han sido seguidos por juicios nacionales $[. . .]_{¿} Y$ podemos esperar que escapemos al castigo tan manifiestamente ganado por nuestros crímenes nacionales? ¿Esperamos que la inmutable ley de justicia sea suspendida o abolida, para que nuestra nación pueda seguir sin castigo?

Giddings respondió con indignación al mensaje anual del presidente en diciembre de 1846, en el que éste recitó una versión dudosa de los orígenes de la guerra. Sus compatriotas, de cuya probidad nunca dudó, inevitablemente se volverían en contra de la guerra:

Es imposible que un pueblo cristiano -un pueblo que adora a un Dios de justiciapueda llevar a cabo una rapaz guerra de conquista como ésta, y gastar su dinero en derramar desventura, devastación y muerte [...] Es imposible que un pueblo cristiano proporcione su aprobación y aliente una guerra dirigida al declarado propósito de extender la esclavitud, de perpetuar la opresión, de abrir nuevos mercados de esclavos para la venta de hombres [...] [Los estadunidensesl están conscientes de que este amplio gasto de dinero y sangre se hace para apoyar el sistema de opresión más nauseabundo que jamás ha maldecido a la familia humana. $^{43}$

Giddings pidió el retiro inmediato de todos los soldados de México. Demandó el cese unilateral de las hostilidades. A éste debía seguir un convenio genuinamente bueno para México, al que se refería como una meritoria "república hermana". ${ }^{44}$ Era un ávido partidario de la legislación de 1846 promovida por el representante David Wilmont (demócrata de Pensilvania) que prohibía la esclavitud en cualquier territorio arrebatado a México. Presentado como una enmienda a un documento de apropiación, la propuesta de Wilmont (Wilmont Proviso) fue aprobada por la Asamblea (con endosos de diez legislaturas de estados del Norte), pero repetidamente fracasó en los exámenes del Senado. Mientras que Lincoln y Webster intentaban calmar los ácidos debates sobre Wilmont o eludirlos, Giddings declaró: "No puede haber compromiso entre bien y mal, entre virtud y crimen." La aprobación de Wilmont privaría al Sur de sus aspiraciones de guerra y, quizá, disminuiría la severidad del castigo divino. ${ }^{45}$

Ante la consternación de la mayoría de los whigs, Giddings votó en contra de medidas de abastecimiento para apoyar al ejército, diciendo que este método apre-

43 "The President's Annual Message", 15 de diciembre de 1846 en Giddings, Speeches, 1968, pp. $265-288$.

${ }^{44}$ Ibid:; George, Life, 1892, p. 195.

45 "The Wilmont Proviso", 13 de febrero de 1847 en Giddings, Speeches, 1968, pp. 202-220; Stewart, Josbua, 1970, p. 131. 
suraría su retiro de México. Censuró a líderes whigs moderados en la Asamblea, en especial a Robert Winthrop de Massachusetts, por timidez ética, manifiesta en su oposición a la guerra pero votando por las apropiaciones. La rudeza de Giddings a este respecto invitaba a la represalia. Winthrop relacionó a Giddings con los federalistas de 1812 de dudoso patriotismo. Esperando distanciar, en la mentalidad de los votantes, la corriente principal del partido de los renegados de Giddings, Winthrop atacó a los extremistas: sus bufonadas y su irresponsabilidad envalentonaban a los mexicanos a pelear. Este reproche provocó una respuesta encolerizada de Giddings y sus aliados periodistas (en especial Greeley del New York Tribune). La escalada resultante amenazó con romper la coherencia whig más allá de la restauración. Giddings acudió al senador Thomas Corvin de Ohio para devolver al partido a la respetabilidad tras de que se lanzó contra la guerra en febrero de 1847. La había reprobado como latrocinio. Pero la obsesión de Giddings por el senador se apagó cuando Corvin repudió a los whigs radicales y denunció la propuesta Wilmont. El aislamiento político entre los whigs tuvo también un lado personal para Giddings. Él y Lincoln cayeron en una disputa de insultos basada en sus diferentes enfoques de la guerra. Su amistad se enfrió. ${ }^{46}$

Giddings emitió en 1848 el único voto en contra de las resoluciones de la Cámara baja del Congreso que honraban a los generales Taylor y Scott por su participación para ganar la guerra. Solicitó

${ }^{46}$ Stewart, Josbua, 1970, pp. 125, 134, 147, 167-168. en vez de ello un voto de agradecimiento a Gallant por publicar sus ensayos pacifistas.

\section{LA RENUENCIA DE CALHOUN}

Adams, Giddings y los polemistas de Nueva Inglaterra difícilmente estaban solos al considerar la guerra como maquinaciones de una conspiración sureña. Esta línea se estableció más tarde como estándar en la historiografía, asociada a estudiosos como James Ford Rhodes: México había sido acicateado para atacar, dando una excusa para una guerra injusta a instancias de la esclavocracia. Los ataques a esta interpretación han sido muchos y variados. Algunos autores han subrayado la importancia de las nociones del Destino Manifiesto para explicar la guerra: no se ocultaba una conspiración, sino una doctrina que celebraba el chauvinismo nacional creando un ambiente permisivo a la agresión. Otros autores han resaltado el papel de los actores principales, especialmente el inflexible Polk. Otros más han recalcado la vulnerabilidad de México en 1846 ante los depredadores -incluyendo Gran Bretaña y Francia-, entre los cuales Estados Unidos era el más cercano. En este espíritu, el hombre fuerte, Porfirio Díaz, aparentemente expresó: “¡Pobre México! ¡Tan lejos de Dios y tan cerca de Estados Unidos!" Friedrich Engels colocó la guerra en el amplio juego de las fuerzas fundamentales de la historia. Efusivamente expresó que la "magnífica California" había sido "arrebatada a los perezosos mexicanos" para ser usada a partir de ahí por los "enérgicos yanquis" de acuerdo con un progreso mundial ordenado. La más fuerte oposición a la visión de Adams- 
Giddings-Rhodes surge de esta evidencia. El preeminente defensor de la esclavitud en la época se oponía a la guerra. Calhoun la desacreditó como "insensatez y extravagancia". ${ }^{47}$

Plantador, dueño de esclavos, demócrata, gracias a la guerra con México tuvo varios puestos en Washington, excepto el que más codiciaba: la presidencia. Calhoun había prestado servicio en la Cámara baja del Congreso (1811-1817), en donde había sido un agitador por la guerra en 1812 y un nacionalista comprometido con poderosas fuerzas armadas, mejoras internas, manufactura moderna y el segundo banco de Estados Unidos. Había trabajado con eficacia como secretario de Guerra de Monroe de 1817 a 1825. Sus periodos como vicepresidente con John Quincy Adams (1825-1829) y Andrew Jackson (1829-1832) habían estado señalados por la controversia que provocó resentimiento entre él y sus jefes. Calhoun inició su carrera en el Senado a finales de 1832. La interrumpió brevemente para servir como secretario de Estado para Tyler (1844-1845), en cuyo carácter aseguró la admisión de Texas como estado esclavo. Hacia 1846, el seccionalismo de Calhoun había eclipsado su anterior aspecto nacionalista. Defendió los derechos de la minoría y la anulación dentro del marco de los estados iguales en convenio. Escribió dos ensayos duraderos a este respecto hacia el final de su vida: Disquisition on

${ }^{47}$ Ruiz, Mexican, 1963, pp. 1-7; Eisenhower, So Far, 1989 , pp. Xv y 374; Friedrich Engels, Democratic Pan-Slavism, 15 de febrero de 1849 en Fernbach, Marx, 1974, pp. 229-230; Calhoun a Thomas Clemson, 15 de junio de 1847 en Wilson y Cook, Papers, 1998, vol. Xxiv, pp. 398-440.
Government y Discourse on the Constitution. Así como menguó su temprana simpatía por una autoridad federal fuerte, también se enfrió hacia 1812 su ardor por la acción dramática. Con la salud decadente y a sus 60 años, comparó el celo de Estados Unidos por la guerra en 1846 con el irreflexivo entusiasmo juvenil: "lleno de salud $\mathrm{y}$ vigor y dispuesto para las aventuras de cualquier índole, pero sin la guía de la sabiduría ni de la experiencia". 48

Esta precipitación se reveló en la manera en que los estadunidenses fueron a la guerra, privados de un mandato del Congreso o de una deliberación cuidadosa. Calhoun también se preocupaba de que la guerra sería larga y costosa. Una guerra larga obligaría a México a buscar seguridad en la protección británica, convirtiéndose en una dependencia de Londres. Por definición sería una zona libre con apoyo poderoso y peligrosamente cerca del Sur esclavista. Sin embargo, a pesar de estas angustias, Calhoun mantuvo un discreto silencio después de los debates de mayo de 1846 sobre la guerra. Otros hubiesen puesto reparos. A él no le gustaba la idea de romper con su presidente o con su partido. Pero a medida que el campo de las operaciones militares creció, a medida que el movimiento "Todo México" ganaba impulso, lo objetó públicamente. Se preguntaba en voz alta si el gobierno sabía lo que estaba haciendo, ya que la incompetencia presidencial se había revelado al apoyar el regreso de Santa

${ }^{48}$ Bartlett, John, 1993, p. 336. Sobre el carácter guerrero de Estados Unidos, véase p. 244 del "First Speech on the Bill for an Additional Military Force", 16 de julio de 1848 en Wilson y Cook, Papers, 1998, vol. xxv, pp. 235-245. 
Anna de La Habana y después con el intento de Polk de dar a Benton el mando principal (Calhoun despreciaba al senador de Missouri -considerándolo un rival para el nombramiento demócrata de 1848 para la presidencia- y ayudó a impedir su generalato). También acusaba a Polk por las derrotas de los demócratas en 1846 y por el mal manejo de la guerra. ${ }^{49}$

En opinión de Calhoun, lo corrosivo de la guerra significaba un grave riesgo de alcance nacional para el republicanismo. Se maravillaba cada vez que los estadunidenses ensalzaban héroes militares, al parecer felices de sustituir su sabiduría por la de la clase política elegida y responsable. El general Taylor particularmente desconcertaba a Calhoun -no sólo porque la popularidad del soldado entre los votantes parecía poder destruir las esperanzas presidenciales de Calhoun. Como cuestión de principio, éste sostuvo que una carrera militar era un pobre aprendizaje para un alto puesto en una democracia representativa. En julio de 1847 cavilaba:

En realidad parece sorprendente, que sólo el talento militar pueda considerarse por una gran mayoría del pueblo estadunidense como el que proporciona la mejor prueba de habilidades de estadista -y es ciertamente un presagio desfavorable, en lo que respecta a la duración de nuestras instituciones. Iré más lejos para admitir que la elección del exitoso general está calculada para impresionar con mayor profundidad la mentalidad del público, la idea de que el talento militar es el único camino seguro hacia los más altos honores civiles, y aumentar, en el

${ }^{49}$ Hietala, Manifest, 1985, p. 243; Lander, Reluctant, 1980, p. 32; Bartlett, Jobn, 1993, p. 340. mismo grado, el espíritu militar del país, que ya es demasiado alto para sus instituciones y para su libertad. ${ }^{\text {so }}$

Calhoun esperaba que los futuros presidentes -asumiendo que sobreviviera algo similar a la democracia estadunidenseserían más circunspectos que Polk. No deberían permitir surgir situaciones en las que los soldados ganaran estatura política. Ciertamente, dijo Calhoun, si Polk hubiese sabido que la guerra haría de un soldado desconocido madera presidencial para el partido de la oposición, la administración hubiese abandonado su senda mexicana. Sólo en casos de necesidad o de clara justicia, persistía Calhoun, debía el gobierno alejar a la nación de la paz. Todas las demás causas eran irrelevantes o triviales. El costo aun de una guerra buena invariablemente incluía la elevación de soldados a un grado malsano. ${ }^{51}$

Calhoun también se desesperaba con la posibilidad de que la Unión absorbiera todo o la mayor parte de México. Consideraba que el impacto sobre el republicanismo estadunidense sería fatal. Si Washington decidía que sus territorios mexicanos no eran aptos para la condición de estados, y que los nacionales mexicanos eran inadecuados para la ciudadanía, entonces los estadunidenses tendrían que gobernar su nueva adquisición como colonia. Este imperio se asemejaría al de España en México o al de Gran Bretaña sobre las trece [colonias]. Pero, advertía, Estados Unidos no podía ser republicano e imperial -ya que una república imperial

${ }^{50}$ Calhoun a Joseph Lesesne, 19 de julio de 1847 en Wilson y Cook, Papers, 1998, vol. xxrv, pp. 462464.

51 Ibid. 
es contradictoria en sus términos. $\mathrm{El} \mathrm{im-}$ perio corrompería el experimento estadunidense de autogobierno, concentrando un poder excesivo en la rama ejecutiva y produciendo instituciones dudosas: procónsules, legiones de tropas de ocupación, ucases. Se dañaría la construcción de Estados Unidos cuando la rama ejecutiva se convirtiera en un despotismo de "esplendor" apabullante. Ni el Congreso ni las pequeñas legislaturas y los gobernadores podrían resistir las pretensiones federales. En suma, las libertades de Estados Unidos se extinguirían simultáneamente con las de México. ${ }^{52}$

En caso de que la autoridad federal concediera derechos de ciudadanía a los mexicanos y reformara sus territorios en nuevos estados, surgirían entonces problemas raciales y políticos impredecibles. La primacía del gobierno blanco en Estados Unidos se desharía. México era una nación híbrida. La sangre de los blancos había sido ampliamente diluida a través de los matrimonios con razas no europeas. Sólo una minoría de mexicanos era de origen español puro. La mayoría era de origen indio o de una mezcla. Algunos eran africanos. Semejante gente carecía del temperamento y de los requisitos para convertirse de verdad en buenos ciudadanos. Calhoun predicaba que la historia reciente de América Latina debía leerse como un relato de advertencia. La impureza racial y la colocación de "razas de color en igualdad con la raza blanca [han] destruido la base social de la sociedad", produciendo revoluciones sangrientas y anarquía. Como mínimo, aun si el prece-

52 "Discurso sobre la guerra con México", 4 de enero de 1848 en Wilson y Cook, Papers, 1998, vol. xxv, pp. 54-95. dente de América Latina no se siguiese, la raza blanca de Estados Unidos se hundiría en la mediocridad extranjera, demasiado obtusa para entender o dominar los protocolos de la democracia. La gente de tez oscura no puede aprender: "es un hecho notable que en toda la historia del hombre [...] no hay algún ejemplo de alguna [...] raza de color que sea capaz de establecer un gobierno popular libre". ${ }^{53}$

La continuación de la esclavitud africana en el sur de Estados Unidos sería imposible en el caso de una unión política con los mexicanos. La inclusión de muchos millones de católicos mexicanos era también un prospecto poco apetecible. Sus correligionarios de la hambruna irlandesa estaban ya encontrando su camino, en números no deseados, hacia lo que era -en el refrán de los know nothings- un país desafiantemente protestante. Calhoun hablaba desde la profundidad de sus creencias cuando preguntó en febrero de 1847:

¿Podemos incorporar a un pueblo tan disímil a nosotros en todo aspecto - $\tan$ poco calificados para un gobierno libre y popular- sin alguna destrucción de nuestras instituciones políticas? ¿Y podemos traer a nuestra Unión 8000000 de individuos, todos profesando una religión $-\mathrm{y}$ todos concentrados bajo un sacerdocio poderoso y rico-, sin someter al país al más violento conflicto religioso, y poniendo al gobierno finalmente bajo el control de una única secta? No. Estas dificultades son insuperables.

Un año más tarde meditaba con escepticismo: " ¿Vamos a asociar con nosotros como iguales, compañeros y conciu-

${ }^{53}$ Ibid. 
dadanos a los indios y a la raza mezclada de México?" Si eso ocurría, Estados Unidos se desintegraría. ${ }^{54}$

En lo referente a la propuesta de Wilmont, Calhoun coincidía con todos los observadores (Polk entre ellos) que creían que la mayoría de los territorios mexicanos eran demasiado áridos para sustentar plantaciones de algodón o a la economía. Esta inadecuación significaba que con probabilidad nunca serían trabajados por agricultores estadunidenses. Pero, decía Calhoun, no debe permitirse que esta realidad práctica lleve a cancelar un trascendental punto teórico: el derecho de los ciudadanos a llevar su propiedad y formas preferidas de vida a las nuevas tierras obtenidas por Estados Unidos. Dicho abiertamente: no se esperaba que los sureños soportaran grandes cargas por la guerra -el regimiento Palmetto de Carolina del Sur sufrió la muerte de $43 \%$ de sus hombres- y a la vez se les negara el ocupar regiones por la propuesta Wilmont. Tal exclusión automática a toda una categoría de ciudadanos obedientes de la ley horrorizaba a Calhoun. Como él y un número creciente de sureños apreciaban, Wilmont significaba que todas las áreas quitadas a México un día constituirían una fila de nuevos estados - quizá quince, todos ellos libres. Éstos operarían con aquellos al norte de Mason-Dixon como un sofocante vínculo alrededor del Sur. Estarían en minoría en las cámaras del Congreso. Serían derrotados en las votaciones de las elecciones nacionales. Su destino se apoyaría en las sobras de simpatía de norteños insensibles. Bajo la égida de Wilmont, el

${ }^{54}$ Ibid.; "Discurso sobre la guerra con México", 9 de febrero de 1847 en Wilson y Cook, Papers, 1998, vol. xxIV, pp. 115-147.
Sur finalmente sucumbiría a un ruidoso conglomerado compuesto por rápidos ferrocarriles, ciudades atestadas, y fábricas que vomitan humo (fabricando hierro, pieles y nuevas cosechadoras de trigo). Calhoun declaraba que si la propuesta de Wilmont fuera hecha ley, entonces el Sur, por las leyes de la autoprotección -para preservar su refinada cultura basada en los ritmos de la naturaleza y las estaciones de pausado crecimiento-, podría dejar la Unión: "El Sur se uniría para oponerse al proyecto. Si [los sureños] cuidan su seguridad, deben anularlo, aun si la Unión se dividiera en dos." Según Polk, en una entrevista privada, Calhoun explicaba que él lucharía contra la ratificación de cualquier tratado mexicano que restringiera la esclavitud. ${ }^{55}$

Para evitar una confrontación seccional sobre la esclavitud, los whigs moderados (los Webster y los Winthrop) propusieron finalizar la guerra sin anexiones. Rehusando el fruto prohibido mexicano (imaginería de Calhoun), Estados Unidos evitaría la expulsión del paraíso de la tranquilidad doméstica. Sin embargo, esa solución al dilema Wilmont no agradó a Calhoun. Un premio de indemnización territorial debía obtenerse de México para validar los agotadores ejercicios de la guerra (y mantener a flote su posición entre los votantes para quienes la guerra era agradable). Aconsejó que Estados Unidos levantara un número de fuertes a lo largo del río Grande hacia el oeste en toda la frontera sur de Nuevo México (paralelo

${ }^{55}$ Lander, Reluctant, 1980, p. 160; Calhoun a Anna Maria Calhoun Clemson, 27 de diciembre de 1846 en Wilson y Cook, Papers, 1998, vol. xxIV, pp. 42-44; entrada del 19 de diciembre de 1846 en Quaife, Diary, 1910, vol. II, pp. 281-284. 
32) hasta el Pacífico. Este territorio no incluía una zona central mexicana, con sus millones de indeseables, sino que correspondía a un área poco poblada del país. Debía ser tomada durante todo el tiempo necesario hasta que pudiera dictaminarse un arreglo final. Este cordón militar, dijo Calhoun a sus colegas congresistas, aseguraría condiciones favorables a las negociaciones y daría la base para la futura reconciliación entre México y Estados Unidos:

Nuestra política auténtica [...] no es debilitar o humillar [a México]; por lo contrario, nuestro interés es verlo fuerte, $\mathrm{y}$ respetable [...] hay una conexión misteriosa entre el destino de este país y el de México, tanto, que su independencia y capacidad de sostenerse a sí mismo son casi esenciales para nuestra prosperidad, y para el mantenimiento de nuestras instituciones como lo son para las suyas.

$\mathrm{Al}$ asegurar la conservación de México, los estadunidenses se ahorratían nuevas confrontaciones entre sí; la precaria Unión del mecanizado Norte y el Sur agrario podía todavía preservarse. ${ }^{56}$

\section{Tratado de Guadalupe Hidalgo}

Hacia la primavera de 1847 Polk encaraba problemas no previstos en la época en que el Congreso autorizó la guerra. Uno de sus generales whig, Taylor, se ha-

${ }^{56}$ Entrada del 24 de diciembre de 1846 en Quaife, Diary, 1910, vol. II, pp. 292-293; "Discurso sobre la guerra con México", 9 de febrero de 1847 en Wilson y Cook, Papers, 1998, vol. xxIv, pp. 115133; Niven, John, 1988, p. 304. bía convertido en un rival potencial para cualquier demócrata nominado en la próxima elección presidencial. Polk había prometido que serviría un único periodo (unas palabras que a la larga lamentó). Sin embargo, como líder del partido quería a uno de los suyos para sustituirlo en la Casa Blanca. La propuesta Wilmont, mientras tanto, había fracturado la unidad demócrata, dejando ver la división seccional. Los intentos de Polk por enmendar conflictos en el partido significaban de algún modo la reconciliación de los simpatizantes de Calhoun con firmes líderes antiesclavistas, como el senador John Hale de New Hampshire. Creía, "más allá de la duda", que la guerra se originó en la "política del gobierno estadunidense [...] para hacer de la extensión de la esclavitud humana su principal [objetivo]". ${ }^{57}$ Tan sólo la idea de un entendimiento amigable entre Hale y Calhoun le dio a Polk una desalentadora impresión: ello determinaba la oposición a él y a la guerra. El alboroto por el "Todo México" también estaba ganando fuerza. El presidente atizaba esta manía con su charla irreflexiva. Sin embargo, no quería en verdad que ese movimiento tuviese éxito. Esperaba cortar partes generosas de México. Sin embargo dudaba, por la angustia de Calhoun, que toda la población pudiera ser integrada a Estados Unidos. Respecto a las operaciones militares, desde el punto de vista de Polk los mexicanos eran refractarios a la derrota. Carecían de suficiente sentido común para rendirse, a pesar del avance de Scott a la capital. A menos que se hiciese algo radical, la guep. 123.

57 Congressional Globe, First, 1848, parte I, 


\section{SECUENCIA}

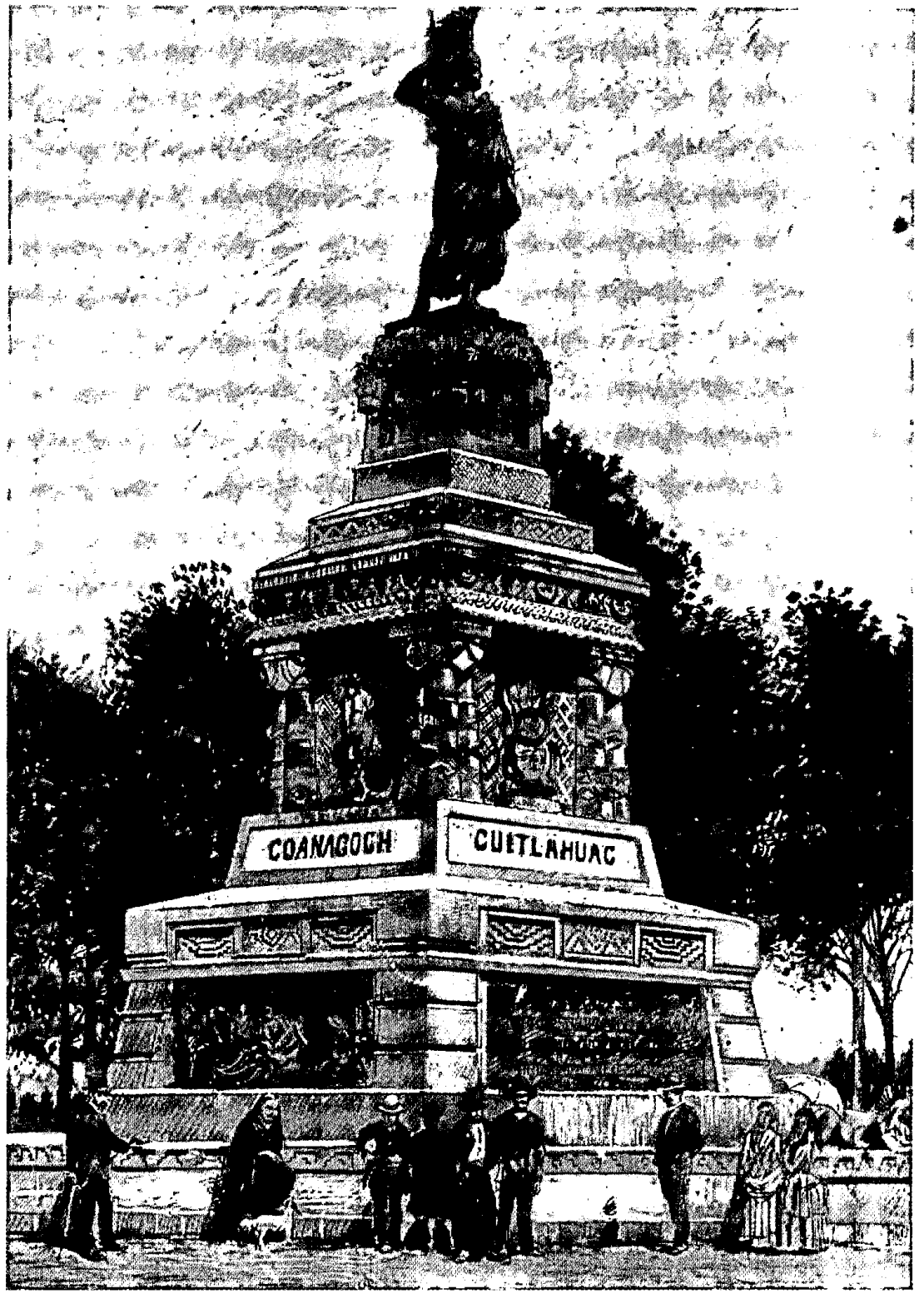


rra continuaría durante años o llegaría a un estancamiento. Los cansados votantes estadunidenses seguramente castigarían al partido político dominante. El "taimado" Santa Anna podía ciertamente ganar por su tenacidad en una guerra de fricciones militares y políticas.

Polk necesitaba librarse de estos dilemas que se acumulaban. Sobre todo, necesitaba terminar la guerra. Su deus ex machina era Nicholas Philip Trist, funcionario principal del Departamento de Estado. Este había pasado inadvertido en la periferia del poder hasta que fue nombrado pacificador en abril de 1847 . Entonces consiguió una suerte de fama: el diplomático menos obediente en la historia estadunidense del siglo XIX.

Sus antecedentes no sugieren una notoriedad futura. Era un virginiano cuya familia había caído en una gallarda ruina. Esta condición no mejoró con su ingreso a West Point, en donde renunció (1821) sin obtener un nombramiento, víctima de mala salud y de desagrado por el régimen militar. Después estudió leyes. Logró ser admitido en la barra de Virginia. Pero la práctica de las leyes lo aburría. La dejó. Se volvió entonces entusiasta del periodismo, al menos durante un tiempo. Adquirió en propiedad el devotamente pro democrático Virginia Advocate. La empresa no floreció bajo sus manos.

Aunque los primeros años de su carrera carecieron de brillo, Trist logró éxito en sus ligas personales. Estas se volvieron vehículos para su avance personal. Se hizo íntimo del anciano Thomas Jefferson, quien dio su bendición al matrimonio de Trist con su nieta, Virginia Jefferson Randolph. Ella alentaba ambiciones en su marido, esperando que un día se sentara en el Tribunal de Justicia de la Suprema
Corte. Entre tanto, Trist se volvió el amanuense de Jefferson. Manejó Monticello. Trabó amistad con el vecino de Jefferson, James Madison. Trist estuvo al lado de Jefferson a la hora de su muerte, el 4 de julio de 1826 . Un efecto de la formación intelectual de Trist, viviendo en este círculo encantador, eta su exageración de las virtudes del antiguo dominio. Esta inclinación era bastante común entre nobles y posibles nobles en un Estado que había proporcionado cuatro de los primeros cinco presidentes de la nación. Para Trist eso era la mejor evidencia de una raza de seres políticos superiores; consideraba que sus residuos se le pegarían por medio de su exposición a Monticello. ${ }^{58}$

Trist recibió su primera encomienda al Departamento de Estado en 1828 como agradecimiento al secretario Henry Clay. Trist permaneció ahí tras las elecciones de 1828 , sobreviviendo a la purga de Andrew Jackson en la burocracia de AdamsClay. Se convirtió en favorito del "Viejo Hickory" y en un invitado frecuente en las cenas de la Casa Blanca. Trist trabajó esporádicamente como secretario personal de Jackson, incluso durante el asunto de Peggy Eaton, cuando el presidente se encontró con un motín en su familia oficial. La lealtad de Trist durante este momento desagradable $-y$ poniéndose del lado del presidente respecto a la anulación y la tarifa-afirmó su amistad..$^{59}$ De esta manera Trist se convirtió en un puente viviente entre el sabio de Virginia y el aristócrata patán. Por medio de ellos se dio forma al partido demócrata. Gracias a ellos, Trist

58 Brent, "Nicholas", 1950, p. 19; Smith, War, 1919, vol. II, pp. 127-128.

59 Brent, "Nicholas", 1950 , pp. 79-85. 
adquirió importancia y una seguridad en sí mismo por demás inmerecida por sus modestos logros.

Jackson premió la fidelidad de Trist con un lucrativo nombramiento consular en La Habana en 1834. Trist estuvo en este cargo durante siete años, hasta que fue perturbado por una indagación en el Congreso por cargos serios. Éstos iban desde acusaciones de capitanes de barco y comerciantes que se quejaban de que adulaba a las autoridades españolas $-\mathrm{y}$ no protegía los intereses estadunidenses-hasta argumentos de que ayudaba al tráfico ilegal de esclavos. ${ }^{60}$ No fue declarado culpable. Pero quedó comprometido. No se quejó cuando el secretario de Estado Daniel Webster lo reemplazó en 1841 con un partidario whig.

Trist consideraba al secretario Buchanan un conocido de la administración de Jackson. Éste escogió a Trist para ser funcionario principal en 1845 -en cuya promoción Jackson desempeñó un papel oculto. Este puesto era el segundo más alto en el departamento, equivalente al de secretario delegado de Estado en las jerarquías posteriores. Trist supervisó en este puesto la rutina diaria del Departamento de Estado, un curioso asunto si se lo mide con las operaciones del siglo XXI. Compuesto de tres oficinas -diplomática, consular, local- el departamento empleaba poco menos de una docena de oficinistas para el manejo de la correspondencia entre Washington y sus ministros dispersos y 150 cónsules. Trist sustituyó a Buchanan durante sus ausencias de Washington. Su cortesía natural y su inteligencia mantuvieron confortablemente a Trist entre la elite de la capital. Los personajes y los

${ }^{60}$ Reeves, American, 1967, pp. 31-32, 312. dignatarios extranjeros rara vez lo criticaban. ${ }^{61}$

Polk eligió a Trist para la diligencia con México por tres razones: su brillo diplomático, su dominio fluido del español y su oscuridad política. En este último caso, aunque su misión no tuviera éxito, el prestigio de Estados Unidos no quedaría seriamente implicado. Tampoco su falta de visibilidad pública y su aparente indiferencia ante un puesto de elección indicaban que se empeñaría totalmente en el objetivo de anteponer los intereses de Estados Unidos tal como eran definidos por Polk. En suma, Trist aparentaba ser un tenaz instrumento diplomático desembarazado de ambiciones políticas que hubieran complicado el asunto. Polk anotó:

Son tantos los celos de las diferentes facciones del partido demócrata respecto a las siguientes elecciones presidenciales, que es imposible nombrar a cualquier hombre $u$ hombres apropiados sin provocar un enorme descontento en los otros, y por consiguiente poner en peligro la ratificación de cualquier tratado que pudiesen pactar. ${ }^{62}$

Estas consideraciones, a pesar de estar bien fundamentadas, omitían ciertas cualidades de Trist que pronto se revelaron por ellas mismas: un orgullo bien arraigado, obstinaciôn y un don para la teatralidad. Es posible que Polk no haya sido por completo ignorante de estos rasgos. Insinuó a Trist que obtendría una buena promoción en el Partido Demócrata si

61 Brent, "Nicholas", 1950, p. 119; Fleming, "Nicholas", 1998, p. 78; Nelson, Secret, 1988, p. 7; Rivers, United States, 1913, vol. II, p. 425.

62 Entrada del 10 de abril de 1848 en Quaife, Diary, 1910, vol. II, pp. 465-469. 
manejaba con aplomo a los mexicanos y al general Scott. ${ }^{63}$

Tras regatear con el gabinete los medios y objetivos -donde Buchanan tomó una postura minoritaria en favor de la mezquindad al tratar con México- se entregaron a Trist las instrucciones. Tenía que ponerse a las órdenes de Scott en el momento que se dirigiera a la ciudad de México. En su oportunidad tenía que ofrecer un pago -hasta por 30000000 - a lo que fuere considerado una autoridad responsable ("tan rápidamente una revolución sigue a otra en México") por Nuevo México, Alta y Baja California, y por el derecho a circular por el istmo de Tehuantepec, que separa al Golfo de México del Pacífico. La compra de Nuevo México y Alta California (con estimables bahías en San Francisco y San Diego) era crucial, "un sine qua non de cualquier tratado". Trist podía invertir hasta 20000000 por ellas. Tehuantepec y Baja California eran menos importantes. No debía actuar indebidamente ante la obstinación mexicana o pagar más de 5000000 por cualquiera de las propiedades. Washington asumiría también la responsabilidad sobre cualquier tratado futuro por reclamaciones financieras de varios ciudadanos estadunidenses contra el gobierno mexicano. El río Grande, claro, señalaría la frontera entre las dos repúblicas. ${ }^{64}$

Polk instruyó a Trist a proceder con el mayor de los sigilos por miedo a que

${ }^{63}$ Graebner, Empire, 1983, pp. 192-194; Pletcher, Diplomacy, 1973, pp. 499-501, 504; Eisenhower, So Far, 1989, pp. 290-291, 298-299; Reeves, American, 1967, p. 311.

${ }^{64}$ Entrada del 13 de abril de 1847 en Quaife, Diary, 1910, vol. II, pp. 471-475; James Buchanan a Nicholas Trist, 15 de abril de 1847 en Manning, Diplomatic, 1937, vol. viII, pp. 201-207. los enemigos domésticos de la administración supieran de otra propuesta a México que implicaba amplias indemnizaciones. Esto fue negado repetidas veces por Polk, quien aseguró que su único objetivo era la restauración de la paz. Sólo si la misión de Trist tenía éxito reconocería Polk su existencia. Con esta inflexibilidad en la cabeza, el enviado inició su difícil viaje a México (duro trayecto en toscos transportes y con mal tiempo). Sin embargo, el velo del secreto fue casi instantáneamente roto por la prensa opositora. Hacia mediados de junio el New York Herald había obtenido la propuesta de Polk para una enorme cesión mexicana. ${ }^{65}$

Complicando el asunto ese mismo mes de junio, los dos principales estadunidenses en México, Scott y Trist, se opusieron violentamente uno a otro. Intercambiaron cartas insultantes y enviaron petulantes informes a sus superiores en Washington. La tempestad llegó a Polk hasta un punto en que éste dudó de la posibilidad del éxito diplomático y consideró si sería bueno retirar a los pendencieros egoístas. El principal problema entre ellos era quién tenía la autoridad para negociar un tratado. Asuntos secundarios se mezclaban con la sospecha de Scott de que Trist era un agente enviado por el "socarrón" Polk para la destrucción del general, y el amour propre de Trist era herido por la aspereza de Scott. Éste, a cargo de un ejército conquistador, fastidió a Trist y le dijo con desprecio que era un funcionario servil.

Tanto el secretario de Guerra William Marcy, como Buchanan, a instancias de Polk, ordenaron a sus pendencieros subor-

${ }^{65}$ Graebner, Empire, 1983, pp. 195-196; Merk, Manifest, 1963, p. 114. 
dinados en México que se reconciliaran. Obedientemente éstos dieron pasos (tentativos) para un acercamiento. Lá tregua sólo ocurrió cuando el diplomático fue doblegado por la fiebre en Puebla. Scott graciosamente "clamó pax". Envió a Trist jalea de guayaba y un saludo amigable. Después, los hombres se hicieron amigos, y a partir de ese momento colaboraron. (Se convirtieron, bajo la visión oscura de Polk, en un intento de los conspiradores para humillar a la administración.) Scott reportó más tarde sobre sus meses en México: "Nunca antes tuve un compañero más amable, tranquilo y caballeroso." Por su parte, un avergonzado Trist pidió en julio al Departamento de Estado que tetirara de sus archivos correspondencia que contuviera calumnias sobre el loable soldado. ${ }^{66}$

El equipo Scott-Trist intentó convencer a las autoridades de México de que pidieran la paz, en tanto que las operaciones militares contra sus ejércitos proseguían en Contreras, Churubusco y Molino del Rey. Por la época en que el ejército de Scott ocupó la ciudad de México (14 de septiembre de 1847), Trist había establecido relaciones de trabajo con diplomáticos ingleses: el ministro Charles Bankhead y el secretario de la legación Edward Thornton. Ellos estaban dispuestos a resguardar para México lo que pudiese salvarse. El imperativo para el gobierno de lord John Russell, congruente con la venerable política de la corona, era vigilar

${ }^{66}$ Brent, "Nicholas", 1950, p. 157; Scott, Memoirs, 1864, vol. II, p. 579; Nicholas Trist a James Buchanan, 23 de julio de 1847 en Manning, Diplomatic, 1937, vol. vill, pp. 915-916; entrada del 24 de enero de 1848 en Quaife, Diary, 191.0, vol. III, pp. 311-313. la expansión del hegemónico del nuevo mundo. Con este propósito el Ministerio de Relaciones Exteriores había asignado antes un papel a México y lo había reforzado con cuantiosos préstamos. ( $\mathrm{Si}$ acaso México incumpliera los préstamos o Gran Bretaña los cancelase, entonces era probable que el gobierno de la reina Victoria pudiera aceptar California como compensación.) Con esta intención, Bankhead alentó a las autoridades mexicanas el verano de 1847 a llegar a un arreglo con Trist, y rogó que éste fuera indulgente. Entre tanto, Thornton presionó a Scott y a Trist sobre la conveniencia de los sobornos, alegando que el dinero, apropiadamente distribuido entre los líderes mexicanos, los convencería de rendirse. Tras una consulta con el Estado Mayor de Scott y superando sus propios escrúpulos, Trist y Scott decidieron poner de inmediato a disposición de Santa Anna 10000 dólares. Él y otros meritorios recibirían un pago de 1000000 de dólares del fondo de contingencia de Scott, tras la firma de un acuerdo de paz. Este "lubricante", sin embargo, no funcionó. El Congreso de México deliberó a mediados de julio sobre la prudencia de iniciar pláticas formales con los estadunidenses. La idea fue rechazada. Santa Anna se guardó la enorme dádiva -no queda claro si para su uso personal o para defensa nacional. Trist juzgó más tarde que Santa Anna "no era patriota, sino justo lo contrario". La lucha se reanudó. ${ }^{67}$

${ }^{67}$ Nicholas Trist a James Buchanan, 13 de junio de 1847 y 27 de septiembre de 1847 en Manning, Diplomatic, 1937, vol. vIII, pp. 908-914, 953-956; Rippy, Rivalry, 1972, pp. 247-248; Pletcher, Diplomacy, 1973, pp. 502-504; Haynes, James, 1997. p. 95; Bauer, Mexican, 1974, pp. 284-286; Castillo, Treaty, 1990, pp. 27-29; Jones, Santa Anna, 1968, pp. 114-115; Caruso, Mexican, 1991, pp. 155-156. 
Los funcionarios de la administración estaban incrédulos al principio, luego iracundos. Buchanan escribió a Trist apenas aparecieron en Washington los rumores del intento de soborno:

El presidente confía con ansia que no os hayáis involucrado en una transacción que cubriría con merecida desgracia a todos los que hubieran participado en ella, y que pondría una mancha indeleble sobre el carácter de nuestro país. ${ }^{68}$

Bastante aparte del fracaso del cohecho, Polk perdió confianza en la eficacia de las negociaciones. La capital de México estaba en manos de los estadunidenses desde mediados de septiembre. Sin embargo existía un estado de guerra sin una conclusión a la vista. En consecuencia, Polk dijo a Buchanan en octubre que retirara a Trist de la ciudad de México y suspendiera las negociaciones. Las futuras negociaciones de paz tendrían que venir de México. Scott debía imponer contribuciones a la población local para sufragar los gastos de su ejército hasta que las pláticas se reanudaran. Respecto a Trist, Polk tenía cada vez menos interés. El enviado había insinuado a interlocutores mexicanos que su propuesta de crear una zona amortiguadora en el territorio entre los ríos Nueces y Grande tenía posibilidades. No rechazó directamente esta idea a expensas de Texas. Y habló de más cuando sugirió que Estados Unidos no tenía intenciones sobre toda California. Al enterarse de esta flexibilidad no autorizada, Polk se indignó:

${ }^{68}$ James Buchanan a Nicholas Trist, 21 de diciembre de 1847 en Manning, Diplomatic, 1937, vol. VIII, pp. 218-219.
Mr. Trist ha manejado la negociación con mucha torpeza y sin habilidad [...] Ha dificultado cualquier negociación posterior con México. A partir de ahora México puede pedir términos igualmente favorables a los que él ha sugerido, y nunca podré aprobarlos, y si se firma un tratado, y México lo ratifica, no lo presentaré al Senado. Estoy muy molesto con la gestión de $\mathrm{Mr}$. Trist. Pensé que era más sagaz. ${ }^{69}$

La carta de Buchanan ordenando su regreso ( 6 de octubre de 1847) le llegó a Trist a mediados de noviembre a la ciudad de México. La siguió otra de reprensión poco después de que insistió en la inviolabilidad de la frontera del río Grande. ${ }^{70}$ Trist fue tomado por sorpresa. Hasta la llegada de estos comunicados había considerado que su conducta correspondía a las órdenes recibidas. Creía también que las negociaciones con los "aturdidos" mexicanos pronto darían resultados que complacerían a Polk. No obstante, notificó a Scott, al gobierno de México (por entonces bajo mando del moderado Manuel de la Peña y Peña) y a la legación británica de su aviso de vuelta. Trist se preparó para regresar a Washington. Sin embargo, por instigación de esta gente y en razón de su propia certeza de que la paz estaba cerca, dudaba. Después, a principios de diciembre, decidió quedarse. Completaría las negociaciones en desafío a las directivas de Buchanan. Advirtió al secretario de Estado en una carta de 65 páginas, repleta de ardiente prosa y autorreivindi-

\footnotetext{
${ }^{69}$ Entrada del 4 de octubre de 1847 en Quaife, Diary, 1910, vol. III, p. 185.

${ }^{70}$ James Buchanan a Nicholas Trist, 6 de octubre de 1847 en Manning, Diplomatic, 1937, vol. vilI, pp. 214-218.
} 
cación, que la paz buscada por Polk estaba a la mano. Pero que, a menos que se aprovechara la oportunidad, se desvanecería "por un periodo indefinido, probablemente por siempre". La postura del gobierno de paz era torpe. Se derrumbaría a menos que cesaran las hostilidades: "Se caerá, y lo hará a menos que la paz [...] se pacte." Estados Unidos quedaría involucrado en una ocupación de duración indefinida y ruinoso costo. Mezclados en esta epístola se encontraban temas adicionales: la falta de desarrollo de México, la desesperada necesidad de amplias reformas, las virtudes de Scott, la indignidad de Pillow. El más relevante tema de Trist era la oposición al concepto de "Todo México", que consideraba erróneamente que era a lo que se inclinaba Polk. La lógica de Trist era totalmente Calhoun (exceptuando que México se uniría en lo futuro a Estados Unidos):

Se me ha hecho considerar esta terrible calamidad [la disolución de la Unión] como un gran bien cuando se la compara con la anexión [...] de este país [México] al nuestro, sea por conquista o por "ocupación", o bien por pacto. Que esta incorporación va a ocurrir -que, en la plenitud del tiempo, debe ocurrir- no tengo duda alguna. Pero no ha llegado la hora en que pueda suceder sin un peligro incalculable para cualquier buen principio, moral o político, que nos es caro, sin la casi segura destrucción de todo aquello de cuya preservación depende la continuación exitosa de nuestro gran experimento para la felicidad de nuestra estirpe. ${ }^{71}$

71 Nicholas Trist a James Buchanan, 6 de diciembre de 1847 en ibid., pp. 984-1020.
Esta preocupación por la felicidad de los estadunidenses se apoyaba en el anticatolicismo de Trist tanto como en un prejuicio racial convencional. Mientras que Polk toleraba capellanes católicos en el ejército de Estados Unidos -y aprovechaba las ventajas de la propaganda de la confiscación, por parte del gobierno mexicano, de propiedades de la Iglesia para financiar la guerra-, Trist tenía horror al papado y a sus obràs. Pocas versiones de ellas podían ser asimiladas en la sociedad estadunidense, y ciertamente ninguna de las bajas variantes mexicanas. En un despacho dirigido a Buchanan, Trist describía a

los perezosos, ignorantes y estúpidos monjes, cuyos objetivos no van más allá de la rutina de gozos meramente animales, de los que están hechas sus vidas, y que no tienen en sus temperamentos un elemento alguno para un esprit de corps, salvo el amor común y la codicia por el dinero y las propiedades, mezclada con un fanatismo de adoración de ídolos (para ellos, la religión es idolatría pura y encendido de velas) no menos obsceno y bajo que su glotonería y lascivia. ${ }^{72}$

Trist se sentía moralmente obligado a preservar a su país blanco, protestante y de habla inglesa, de una apropiación silenciosa -ocultada por la anexión- por parte de morenos católicos de habla española. La coherencia social de Estados Unidos estaba en juego; el bienestar nacional desafiaba las órdenes de los superiores, aun las pronunciadas por la Casa Blanca. ${ }^{73}$

Más allá del alcance de la furia de Polk ante esta insubordinación, y en compañía

${ }^{72}$ Nicholas Trist a James Buchanan, 25 de octubre de 1847 en ibid., pp. 958-964.

${ }^{73}$ Schoultz, Beneath, 1998, p. 34. 
de quienes lo apoyaban, 'Trist concluyó su parte en las negociaciones. Éstas culminaron en un tratado el 2 de febrero de 1848 , firmado en un sitio sagrado para los mexicanos: Guadalupe Hidalgo, en donde supuestamente la Virgen María se apareció en 1531. Los firmantes mexicanos incluían a Luis Gonzaga Cuevas (antes ministro del Exterior) y José Bernardo Couto (abogado prominente). Éstos estaban prestos a pactar con Trist por miedo a que su sucesor o los acontecimientos exigieran mayores decomisos. El tratado no cedía derechos de paso por Tehuantepec como los británicos habían solicitado antes. Tampoco cedía Baja California a Estados Unidos. Virtualmente todo lo demás especificado por Polk a Trist en 1847 se obtuvo -a la mitad del costo que había estipulado pagar. (El gobierno de Estados Unidos también asumió 3250000 dólares reclamados por sus ciudadanos en contra de México. $)^{74}$

La llegada a Washington del texto del tratado el 19 de febrero de 1848 , transportado por el exánime James Freaner -periodista y admirador de Trist-, planteó un nuevo problema para el gabinete de Polk. El tratado podía ser rechazado porque había sido pactado por un agente sin legitimidad y repelente para Polk: "Ha obrado peor que cualquier hombre en un puesto público que haya yo conocido. Carece de honor y de principios." ${ }^{15}$ Sin embargo, el contenido del documento, si no incluía todo lo que se buscaba, sí era defendible. No merecía su rechazo a

${ }^{74}$ Tratado de Guadalupe Hidalgo en Bevans, Treaties, 1937, vol. IX, pp. 791-806; Weber, Mexican, 1982, p. 274.

${ }^{75}$ Entrada del 15 de enero de 1848 en Quaife, Diary, 1910, vol. III, pp. 300-302. causa de la mala conducta de Trist. También la paz con México era todavía enormemente valiosa. Polk decidió presentar el tratado para la ratificación del Senado. Los secretarios Buchanan y Walker no estuvieron de acuerdo. El primero argumentaba con fuerza exigiendo más territorio mexicano hacia el sur (hasta la montaña de la Sierra Madre). ${ }^{76}$

El debate en el Senado fue vehemente, su resultado incierto al principio. Calhoun cabildeó mucho por el tratado. Pero los defensores de nada de territorio (Webster) y los abogados de más (Sam Houston) se oponían a varias medidas. Nadie expresó una palabra amable para Trist. Finalmente, el Senado ratificó su tratado (con modificaciones menores) en marzo de 1848 con un margen de 38 a catorce. La justicia se había hecho, dijo el senador Douglas, y con ella se garantizó la seguridad de Estados Unidos:

La guerra fue impuesta a nosotros por México [...] [Éste] realizó el ataque; nosotros lo repelimos, y llevamos la guerra al país enemigo con el objeto de obtener una indemnización por el pasado, y, si gustáis, seguridad para el futuro -la seguridad de que nunca inicie nuevamente la guerra en contra de nosotros. $^{77}$

El mordaz experto Philip Hone dio este veredicto sobre el tratado de Trist: ha sido "negociado por un agente no autorizado, con falta de reconocimiento del gobierno y presentado por un presidente

\footnotetext{
${ }^{76}$ Entradas del 19 de febrero de 1848 y del 21 de febrero de 1848 en ibid., pp. 344-346, 347-351.

${ }^{77}$ Congressional Globe, First, 1848, parte I,
} p. 501 . 
accidental a un Senado insatisfecho". ${ }^{78}$ Un agitado parlamento mexicano aceptó el tratado en mayo, tras feroces debates: la Cámara de Diputados con un voto de 51 a 35, el Senado por 33 a cuatro. ${ }^{79}$ Las tropas estadunidenses salieron de la ciudad de México en junio.

\section{CONSIDERACIONES FINALES}

Thoreau era audaz en sus expresiones: "No es demasiado pronto para que el hombre honesto se rebele y haga una revolución." Trist era audaz en obras. El pago por su descontento fue desigual. Thoreau fue incomodado por el encarcelamiento de una noche, justificado por su mediación en la desobediencia. Ello ha conmovido a una tribu de inspirados buscapleitos, incluyendo a León Tolstoi, Emma Goldman, Mahatma Gandhi y Martin Luther King. El ensayo de Thoreau conserva hasta estos días un sitio respetado en el canon estadunidense. ${ }^{80}$

Trist se convirtió en paria. Fue arrestado en la ciudad de México por el general Butler en marzo de 1848 por no obedecer la orden de dejar la capital dada por Buchanan. Aquél ordenó a Trist hacer sus maletas y partir rumbo a Washington. Una helada recepción lo esperaba. ${ }^{81}$ Polk decretó que Trist no recibiera ningún salario posterior a la fecha en que recibió su

${ }^{78}$ Bauer, Mexican, 1974, p. 399.
${ }^{99}$ Castillo, Treaty, 1990 , p. 53.
${ }^{80}$ Tolles, "Henry", 1966 , pp. $338-340$.
${ }^{81}$ El embajador Hermann Eilts observó a favor de Trist: "Con toda seguridad no recomendaría a cualquier diplomático estadunidense joven seguir el ejemplo de Trist, pero puede argüirse que la época y las frías comunicaciones exigían un mayor ejercicio llamado a volver (16 de noviembre de 1847). Ni tampoco que le fueran reembolsados sus gastos en México. El puesto de funcionario principal había sido ocupado desde la partida de Trist de Washington (por William Derrick, de Maine). No se le encontró otro sitio en el Departamento de Estado. Los senadores no tenían necesidad de él. Ni Calhoun ni otros de los que apoyaban el tratado se movieron a favor de Trist. Ignoraron su sugerencia, hecha ante el liderazgo whig de la Cámara baja del Congreso, de que Polk fuese impugnado. Trist nunca ganó su readmisión en el servicio público de altura. En vez de ello fue reubicado en West Chester, Pensilvania. Ahí consiguió empleo como funcionario menor en el Ferrocarril Wilmington y Baltimore. Más adelante logró ascender a cajero. Su esposa ayudó a dirigir una escuela de niñas que fracasó. En su desolación -acentuada por la pobreza y la mala salud- sólo un puñado de individuos se preocuparōn por él. Uno, cuyo aprecio no falló, fue el general Scott. Públicamente se lamentó en 1864 de las dificultades de Trist: "Pobre y conservando todos sus buenos hábitos y su talento, [Trist] ha sido extrañamente despreciado por este gobierno." Sólo tras la guerra civil, durante el primer periodo del presidente Grant, parecieron mejorar sus problemas. Charles Summer, importante líder republicano, notando lo útil de la oposición de Trist al "Todo México", persuadió al Congreso de indemnizar los retrasos del gobierno. Los salarios y gastos no liquidados de Trist, junto con 23 años

de la discreción diplomática del que se permite ahora, cuando las instrucciones se reciben en Washington en unos minutos sobre cualquiera y todos los asuntos concebibles." Eilts al autor, 3 de septiembre de 2001. 
de intereses, se pagaron en 1871: 14600 dólares. Por orden del senador Simon Cameron (republicano, de Pensilvania), Grant también nombró a Trist director general de Correos en Alexandria, Virginia. Pasaba entonces de los 70 años. Su muerte en 1874 fue poco comentada. ${ }^{82}$

Las sanciones entre los extremos de Thoreau y Trist se impusieron a los impugnadores de la guerra. Todos ellos tuvieron que soportar acusaciones de deslealtad. Los halcones de guerra whig de Illinois estaban furiosos contra Lincoln. Las interrogantes sobre su patriotismo lo persiguieron durante años después de la guerra. Stephen Douglas lo acusó en la carrera por el Senado en 1858 de no apoyar a su país durante una emergencia -el consentir en retener abastos de los soldados en el frente. Polk quedó convencido de que Calhoun era antipatriótico y lo obstaculizaba en el Partido Demócrata. Este desahucio terminó para siempre con sus oportunidades presidenciales, al tiempo que alentaba su idea romántica de encontrar un partido político sureño capaz de defenderlo y llevarlo a la Casa Blanca. En lo que respecta a gente como Gallatin, Giddings, Webster y Hale, fueron rutinariamente acusados de prolongar la guerra alentando la resistencia mexicana, que confiaba en hacer tropezar las determinaciones de Estados Unidos. ${ }^{83}$

${ }^{82}$ Scott, Memoirs, 1864, vol. II, p. 580; Fleming, "Nicholas", 1998, p. 84; Merk, Manifest, 1963 , p. 184, núm. 5; Brent, "Nicholas", 1950, pp. 238, 243-246, 248.

${ }^{83}$ Donald, Lincoln, 1995, pp. 128, 133, 40, 226; Cuarto debate Lincoln-Douglas, 18 de septiembre de 1858 en Fehrenbacher, Abrabam, 1989, pp. 636684; entrada del 6 de abril de 1847 en Quaife, Diary, 1910, vol. II, pp. 457-459; Niven, John, 1988, p. 309; Wiltse, Jobn, 1968, p. 319.
Este último argumento no tuvo seguimiento. Era fácil de asestar, pero difícil de probar. También, como decían las víctimas a las que se destinaba, erraba el blanco en una democracia, aun en una democracia en guetra. Las evidencias de fuentes mexicanas nunca corroboraron la acusación. Mariano Otero, de la Cámara de Diputados, citó ciertamente a los whigs y al disentimiento de Nueva Inglaterra en 1848 como una razón para perseverar. Esperaba que el cansancio de Estados Unidos por la guerra, combinado con una resistencia de guerrillas, podía producir mejores condiciones para México. Pero este punto de vista no era compartido por muchos de sus camaradas. Él fue uno de sólo cuatro diputados que votaron a favor de continuar la guerra. Manuel Crescencio Rejón, otro diputado, mencionó la irregularidad del estatus de Trist como una razón para rechazar el Tratado de Guadalupe Hidalgo. Pero esta preocupación era tếcnica. No tenía relación con el deseo de Trist -desconocido para Rejón-: que México debía continuar como una entidad separada de Estados Unidos. La verdadera base para el rechazo de Rejón al tratado tenía que ver con el nublado futuro político-económico de México. Le preocupaba también el destino de los ciudadanos abandonados entre gente con prejuicios raciales: "Los estadunidenses nos odian."

La derrota infligió una crisis de confianza a la elite política de México, subrayada por una oferta en 1848 para ungir a Scott líder nacional. ${ }^{85} \mathrm{La}$ inestabilidad entorpeció el campo político durante dé-

${ }^{84}$ Robinson, View, 1989, p. 2; Rivers, United States, 1913, vol. II, p. 647; Castillo, Treaty, 1990, pp. 49-51.

${ }^{85}$ Scott, Memoirs, 1864, vol. II, pp. 581-582. 
cadas. Un levantamiento de campesinos indígenas sacudió la península de Yucatán inmediatamente después de la guerra. Liberales y tradicionalistas intercambiaron recriminaciones. Cada facción acusó a la otra por la carencia de preparación militar en 1846. El jactancioso Santa Anna volvió al poder como "dictador perpetuo" en 1853; fue depuesto en 1857. Benito Juárez y sus asociados redactaron una constitución liberal en 1857, en la que se reducían los privilegios de la Iglesia y del ejército. Le siguieron acciones conservadoras. Esto precipitó una guerra civil en 1858-1861. Triunfó Juárez. Pero fracasaron mayores intentos de reforma. Más adelante Díaz estableció un periodo de gobierno de hierro. Las desigualdades que produjo dieron pie a una nueva ronda de amargura: la revolución de 1910. En el ínterin, el fracaso de Gran Bretaña como protector distante impulsó a los gobiernos mexicanos a buscar en otra parte una garantía contra Estados Unidos. Napoleón III presentó el interés de Francia en 1864 en la persona de Fernando Maximiliano. En 1917 Alemania intentó obtener algo del resentimiento mexicano: la mala jugada de Zimmerman.

En lo que respecta a Estados Unidos, la guerra dividió al país en dos zonas aisladas: Norte y Sur. Calhoun desesperaba en 1847 de que, por primera vez desde su ingreso a la vida pública, no podía imaginar mejores tiempos en el futuro: "[La guerra] ha tendido una cortina entre el presente y el futuro, que me es impenetrable." Sólo sabía que los ejércitos de Estados Unidos estaban obteniendo una portentosa victoria. ${ }^{86}$ Un año más tarde

\footnotetext{
${ }^{86}$ Calhoun a Anna Maria Calhoun Clemson, 27 de diciembre de 1846; Calhoun a Sarah Mytton Mau-
}

los whigs y los demócratas antiesclavistas fundaron el partido Tierra Libre (Free Soil Party); esto condujo al Partido Republicano a tener su base en el Norte. El Sur permaneció siendo predominantemente democrático.

Calhoun murió, al tiempo que Henry Clay conjuraba el Compromiso de 1850. Éste admitía a California como estado libre, pero retrasaba las decisiones sobre la esclavitud en cualquier parte del territorio cedido por México, y permitía leyes sobre esclavos fugitivos más estrictas. Más tarde, el decreto Kansas-Nebraska de 1854 permitió que los colonos decidieran por ellos mismos -soberanía popular-si se permitía la esclavitud al norte de la línea establecida por el Compromiso de Missouri de 1820. La violencia invadió Kansas. Los border ruffians (rufianes fronterizos) atacaron Lawrence en mayo de 1856. La banda de John Brown tomó represalias contra los dueños de esclavos a lo largo del Pottowatomie Creek. Los desórdenes empeoraron. La "sangrante Kansas" no entró a la Unión hasta enero de 1861. Unos meses más tarde el fuerte Sumter, en la bahía de Charleston, fue bombardeado por secesionistas del Sur y obligado a rendirse. Haciendo eco del temor de Giddings en 1846 sobre el destino de la beligerancia de Estados Unidos, Grant escribió tras el fratricidio de 1861-1865: "La rebelión del Sur fue en mucho el producto de la guerra con México. Las naciones, como los individuos, son castigadas por sus transgresiones." ${ }^{87}$

ry, 18 de febrero de 1847; Discurso en respuesta a Thomas $\mathrm{H}$. Benton sobre la guerra con México, 24 de febrero de 1847 en Wilson y Cook, Papers, 1998, vol. xxiv, pp. 42-44, 164-165, 195-210.

${ }^{87}$ Schoultz, Beneath, 1998, p. 38. 
A lo largo de la historia entre México y Estados Unidos, la culpa y el remordimiento en este último país han propiciado un tipo semejante a Giddings, como cuando en los años 1960 el senador Robert Kennedy calificó la guerra con México como una desgracia. ${ }^{88} \mathrm{Sin}$ embargo, esos sentimientos nunca se han traducido en llamados para una retrocesión de las tierras tomadas en 1848.

La tenacidad de las categorías racistas de pensamiento y condescendencia han sido también notables. Calhoun y Trist, extrañamente cruciales para la preservación de México, hubiesen comprendido las reflexiones de George Kennan en 1950 . Este arquitecto de la primera política de la guerra fría atribuía las desventuras de México a su mezcla racial, una mezcolanza de españoles conquistadores y nativos traumatizados:

He aquí la verdadera ilustración de crímenes de los padres infligidos a su progenie; pues, a medida que los españoles se unían en matrimonio con estos pueblos nativos a quienes se había interrumpido tan brutalmente el curso de su historia, tenían que compartir las heridas y debilidades que ellos mismos habían infligido.

Para Kennan, las neurosis y debilidades resultantes explicaban los defectos políticos congénitos de México. Éstos, a su vez, disminuían la probabilidad de una intimidad angloamericana con este país. ${ }^{89}$ Ciertamente, hacia principios del siglo

${ }^{88}$ Richards, Life, 1986, p. 186.

${ }^{89}$ Reporte sobre un viaje a América del Sur, 29 de marzo de 1850 , p. 5, caja 18 , Archivo George Kennan Papers, Princeton University.
XXI, nada semejante a la confianza de Trist ha sido validado: "La incorporación va a suceder [...] No tengo duda." Un régimen de mediana utilidad económica (TIC) y los inmigrantes que buscan una vida mejor en Estados Únidos creyeron en esa profecía.

\section{Bibliografía}

-Adams, Charles Francis (comp.), Memoirs of Jobn Quincy Admas, J. B. Lippincott, Filadelfia, 1877.

-Bartlett, Irving, John C. Calhoun: A Biography, W. W. Norton, Nueva York, 1993.

-Bauer, K. Jack, The Mexican War, 18461848, University of Nebraska Press, Lincoln, 1974.

-Beard, Charles y Mary Beard, Basic History of the United States, Doubleday, Garden City, 1960.

-Bevans, Charles (comp.), Treaties and Other International Agreements of the United States of America, Department of State, Washington, 1937.

-Brack, Gene, Mexico Views Manifest Destiny, 1821-1846: An Essay on the Origins of the Mexican War, University of New Mexico Press, Albuquerque, 1975.

-Brent, Robert Arthur, "Nicholas Philip Trist: Biography of a Disobedient Diplomat", tesis de doctorado, University of Virginia, 1950.

-Brewer Stewart, James, Josbua R. Giddings and the Tactics of Radical Politics, The Press of Case Western Reserve University, Cleveland, 1970.

-Caruso, A. Brooke, The Mexican Spy Company: United States Covert Operations in Mexico, 1845-1848, McFarland and Company, Jefferson, Carolina del Norte, 1991.

-Castillo, Richard Griswold del, The Treaty of Guadalupe Hidalgo, University of Oklahoma Press, Norman, 1990. 
-Congressional Globe, Appendix, First Session of the Twenty-Ninth Congress, Blair and Rives, Washington, 1846.

- First Session of the Twenty-Ninth Congress, Blair and Rives, Washington, 1846.

- The First Session of the Thirtieth Congress, Blair and Rives, Washington, 1848.

-Chaney, Homer Camp, "The MexicanUnited States War as Seen by Mexican Intellectuals, 1846-1956", tesis de doctorado, Stanford University, 1959.

-Crawford, Ann Fears (comp.), The Eagle: The Autobiograpby of Santa Anna, The Pemberton Press, Austin, 1967.

-DeVoto, Bernard, The Year of Decision 1846, Little, Brown, Boston, 1943.

-Donald, David, Lincoln, Simon and Schuster, Nueva York, 1995.

-Eisenhower, John, So Far from God: The U.S, War with Mexico 1846-1848, Random House, Nueva York, 1989.

-Fehrenbacher, Don (comp.), Abrabam Lincoln: Speeches and Writings 1832-1858, The Library of America, Nueva York, 1989.

-Fernbach, David (comp.), Karl Marx: The Revolutions of 1848, Vintage Books, Nueva York, 1974.

-Ferguson, E. James (comp.), Selected Writings of Albert Gallatin, Indianapolis, The BobbsMerrill Company, 1967.

-Fleming, Thomas, "Nicholas Trist: The Disobedient Diplomat" en Susan Ware (comp.), Forgotten Heroes, The Free Press, Nueva York, 1998.

-Fuller, John, Movement for the Acquisition of All Mexico 1846-1848, The Johns Hopkins Press, Baltimore, 1936.

-George, Julian, The Life of Joshua Giddings, A. C. McClurg, Chicago, 1892.

-Giddings, Joshua R., Speeches in Congress, Negro Universities Press, Nueva York, 1968.

-Graebner, Norman, Empire on the Pacific: A Study in American Continental Expansion, ABC. Clio, Santa Barbara, 1983.
-Haynes, Sam, James K Polk and the Expansionist Impulse, Longman, Nueva York, 1997.

-Hietala, Thomas, Manifest Design: Anxious Aggrandizement in Late Jacksonian America, Cornell University Press, Ithaca, 1985.

-Horsman, Reginald, Race and Manifest Destiny: The Origins of American Racial Anglo-Saxonism, Harvard University Press, Cambridge, Mass., 1981.

-Hunt, Michael, Ideology and U.S. Foreign Policy, Yale University Press, New Haven, 1987.

-Iriye, Akira, From Nationalism to Internacionalism: U.S. Foreign Policy to 1914, Routledge and Kean Paul, Londres, 1977.

-Johannsen, Robert, To the Halls of the Montezumas: The Mexican War in the American Imagination, Oxford University Press, Nueva York, 1985.

-Jones, Oakah, Santa Anna, Twayne Publishers, Nueva York, 1968.

-Lander, Ernest McPherson, Reluctant Imperialists: Calboun, the South Carolinians, and the Mexican War, Louisiana State University Press, Baton Rouge, 1980.

-Livermore, Abio Abbot, The War with Mexico Revieuved, American Peace Society, Boston, 1850.

-Manning, William (ed.), Diplomatic Correspondence of the United States: Inter-american Affairs 1831-1860, Carnegie Endowment for International Peace, Washington, 1937.

-Mayer, Henry, All on Fire: William Lloyd Garrison and the Abolition of Slavery, St. Martin's Press, Nueva York, 1998.

-McDougall, Walter, Promised Land, Crusader State: The American Encounter with the World Since 1776, Houghton Mifflin Company, Boston, 1997.

-McEniry, Marie, Sister Blanche, American Catbolics in the War with Mexico, The Catholic University of America, Washington, 1937.

-Merk, Frederick, Manifest Destiny and Mission in American History: A Reinterpretation, Alfred A. Knopf, Nueva York, 1963. 
-Miller, Robert Ryal, Shamrock and Sword: The Saint Patrick's Bataillon in the U.S.-Mexican War, University of Oklahoma Press, Norman, 1989.

-Moody, Loring, Facts for the People: Showing the Relations of the United States Government to Slavery (1847), Freeport, Books for Libraries Press, Nueva York, 1971.

-Morison, Samuel Eliot, The Oxford History of the American People, Oxford University Press, Nueva York, 1965.

-Morison, Samuel Eliot, Frederick Merk and Frank Freidel, Dissent in Three American Wars, Harvard University Press, Cambridge, Mass., 1970.

-Nelson, Anna Kasten, Secret Agents: President Polk and the Search for Peace with Mexico, Garland Publishing, Nueva York, 1988.

-Niven, John, John C. Calboun and the Price of Union: A Biography, Louisiana State University Press, Baton Rouge, 1988.

-Otis, Singletary, The Mexican War, The University of Chicago Press, Chicago, 1960.

-Parker, Theodore, Sermon of War, Charles C. Little and James Brown, Boston, 1846.

-Paz, Octavio, The Labyrinth of Solitude: Life and Thought in Mexico, Grove Press, Nueva York, 1961.

-Pleasant, Stovall, Robert Toombs: Statesman, Speaker, Soldier, Sage, Cassell Publishing Company, Nueva York, 1892.

-Pletcher, David, The Diplomacy of Annexation: Texas, Oregon, and the Mexican War University of Missouri Press, Columbia, 1973.

-Quaife, Milo Milton (comp.), The Diary of James K. Polk, A. C. McClurg and Company, Chicago, 1910.

-Reeves, Jesse, American Diplomacy under Tyler and Polk, Peter Smith, Gloucester, Mass., 1967.

-Richards, Leonard, The Life and Times of Congressman Jobn Quincy Adams, Oxford University Press, Nueva York, 1986.
-Richardson, James (comp.), Messages and Papers of the Presidents, Bureau of National Literature, Nueva York, 1897.

-Rippy, J. Fred, Joel Poinsett, Versatile American, Greenwood Press, Nueva York, 1968.

$\longrightarrow$ - Rivalry of the United States and Great Britain Over Latin America, 1808-1830, Octagon Books, Nueva York, 1972.

-Rivers, George Lockhart, The United States and Mexico 1821-1848, Charles Scribner's Sons, Nueva York, 1913.

-Robinson, Cecil (comp.), The View from Chapultepec: Mexican Writers on the Mexican-American War, The University of Arizona Press, Tucson, 1989.

-Rossi, William (comp.), Henry David Thoreau: Walden and Resistance to Civil Government, Norton and Company, Nueva York, 1992.

-Ruiz, Ramón Eduardo (comp.), The Mexican War: Was It Manifest Destiny?, Holt, Rinehart y Winston, Nueva York, 1963.

-Saul, Norman, Distant Friends: The United States and Russia, 1763-1867, University Press of Kansas, Lawrence, 1991.

-Schoultz, Lars, Beneath the United States: A History of U.S. Policy Toward Latin America, Harvard University Press, Cambridge, Mass., 1998.

-Schroeder, John, Mr. Polk's War: American Opposition and Dissent, 1846-1848, The University of Wisconsin Press, Madison, 1973.

-Scott, Winfield, Memoirs, Sheldon and Company Publishers, Nueva York, 1864.

-Smith, Justin, The War with Mexico, The Macmillan Company, Nueva York, 1919.

-Stephanson, Anders, Manifest Destiny: American Expansionism and the Empire of Right, Hill and Wang, Nueva York, 1995.

-Stewart, Joshua R. Giddings and the Tactics of Radical Politics, The Press of Case Western Reserve University, Cleveland, 1970.

-Tolles, Frederick, "Henry David Thoreau" en Daniel Boorstin (comp.), An American Primer, The University of Chicago Press, Chicago, 1966. 


\section{SECUENCIG}

-U.S. Grant, Personal Memoirs, University of Nebraska Press, Lincoln, 1996.

-Ware, Susan (comp.), Forgotten Heroes, The Free Press, Nueva York, 1998.

-Weber, David, The Mexican Frontier, 1821 1846: The American Soutbwest Under Mexico, University of New Mexico Press, Albuquerque, 1982.

-Wilson, Clyde y Shirley Cook (comps.), The Papers of Jobn C. Calboun, University of South Carolina Press, Columbia, 1998.
-Wiltse, Charles (comp.), The Papers of Daniel Webster: Correspondence, University Press of New England, Hanover, 1984.

- The Papers of Daniel Webster: Speeches and Formal Writings, 1832-1852, University Press of New England, Hanover, 1988.

- Jobn C. Calboun: Sectionalist, 18401850, Russell and Russell, Nueva York, 1968. -Wortham, Thomas (comp.), James Russell Lowell's The Biglow Papers, Northern Illinois University Press, DeKalb, 1977. 